\title{
Regional Structure of the Indian Summer Monsoon in Observations, Reanalysis, and Simulation
}

\author{
Benjamin A. Cash, ${ }^{*}$ James L. Kinter III, ${ }^{*},+$ Jennifer AdAms, ${ }^{*}$ Eric Altshuler, ${ }^{*}$

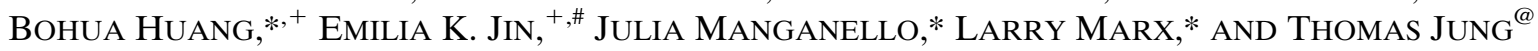 \\ * Center for Ocean-Land-Atmosphere Studies, Fairfax, Virginia \\ ${ }^{+}$George Mason University, Fairfax, Virginia \\ ${ }^{\#}$ Korea Institute of Atmospheric Prediction Systems, Seoul, Korea \\ ${ }^{\circledR}$ Alfred-Wegener-Institute for Polar and Marine Research, Bremerhaven, Germany
}

(Manuscript received 22 April 2014, in final form 10 November 2014)

\begin{abstract}
Regional variations in seasonal mean Indian summer monsoon rainfall and circulation for the period 19792009 are investigated using multiple data products. The focus is on four separate regions: the Western Ghats (WG), the Ganges basin (GB), the Bay of Bengal (BB), and Bangladesh-northeastern India (BD). Data reliability varies strongly by region, with particularly low correlations between different products for the $\mathrm{BB}$ and $\mathrm{BD}$ regions. Correlations between regions are generally not statistically significant, indicating rainfall varies independently in these four regions. The diagnosed associations between rainfall, circulation, and sea surface temperatures can be sensitive to the choice of rainfall product, and multiple precipitation products may need to be analyzed in this region to ensure that the results are robust.

Enhanced precipitation in the BD region is associated with anomalous anticyclonic circulation at $850 \mathrm{mb}$ and westerly anomalies along the foothills of the Tibetan Plateau, while precipitation in the other regions is associated with cyclonic flow and easterlies. These associations provide a dynamical explanation for previously reported weak, negative correlations between $\mathrm{BD}$ and the other regions.

In addition to observed products, atmosphere-only simulations made using the European Centre for Medium-Range Weather Forecasts (ECMWF) Integrated Forecast System (IFS) during Project Athena are analyzed. While the simulations do not reproduce the observed interannual variations in rainfall, the fidelity of the simulated precipitation and circulation structure is comparable to or even outperforms the different state-of-the-art reanalysis products considered. Accuracy in representing interannual variability and regional structure thus appears to be independent.
\end{abstract}

\section{Introduction}

The Indian summer monsoon (ISM) is one of the most significant features of the global climate system, both as a meteorological phenomenon and in terms of its impact on society. Interannual variations in the strength of the monsoon affect not only global weather patterns, but also the lives and livelihoods of fully half the world's population. Understanding variations in the strength of the monsoon is thus clearly of tremendous importance to both science and society, and it has rightfully attracted

Corresponding author address: Benjamin A. Cash, Center for Ocean-Land-Atmosphere Studies, 287 Research Hall, Mail Stop 6C5, George Mason University, 4400 University Dr., Fairfax, VA 22030.

E-mail: bcash@gmu.edu intensive study dating from the early twentieth century through the present day (e.g., Walker and Bliss 1932; Krishnamurthy and Kinter 2003; Turner and Annamalai 2012).

Although analysis of the monsoon is often discussed in terms of large-scale measures of monsoon rainfall and circulation, it is well established that rainfall varies significantly from region to region (e.g., Parthasarathy et al. 1996; Vecchi and Harrison 2004). Using rain gauge data from 29 Indian meteorological subdivisions stretching back to 1871, Parthasarathy et al. (1996) identified five contiguous, homogeneous regions of rainfall that showed varying degrees of positive and negative correlation with each other. Additional work by Vecchi and Harrison (2004) established that $90 \%$ of all-India rainfall (AIR) variability in the Climate Prediction Center Merged Analysis of Precipitation dataset (CMAP; Xie and Arkin 
1996, 1997) since 1982 could be explained by considering indices defined for just two regions: the Western Ghats (WG) and the Ganges basin (GB; see below for definitions). These two regions represent a blend of the regions identified in Parthasarathy et al. (1996) [cf. their Fig. 1 to Plate 2 in Vecchi and Harrison (2004)], and seasonal rainfall totals in the WG and GB were not significantly correlated. These regional rainfall variations, as opposed to large-scale averages such as AIR, are important drivers for numerous local ecological and agricultural processes. Hence, identifying and understanding these variations are critical for a number of important societal concerns, including public health (e.g., Pascual et al. 2000, 2008; Rodó et al. 2002; Cash et al. 2008a, 2009, 2010, 2013).

While Parthasarathy et al. (1996) and Vecchi and Harrison (2004) clearly demonstrate that rainfall within India can be represented by a relatively small number of subregions; these studies are not without limitations. They focus exclusively on rainfall over land across India, and as a result rainfall from other areas of the monsoon region, such as Bangladesh, Myanmar, and the Bay of Bengal, is not considered. This is despite the fact that these subregions include some of the summer monsoon's highest rainfall rates (see below). Each study also makes use of a single rainfall product and, thus, does not address the potential impact of observational uncertainty on their results. Previous work (Cash et al. 2008b) has identified significant differences among observed rainfall products in this region and shown that these differences have a distinctive geographical structure.

In this work, we expand upon these previous studies to consider the regional structure of rainfall across the broader monsoon region, including Bangladesh, Myanmar, and the Bay of Bengal. We explicitly address the sensitivity of our results to observational uncertainties in seasonal monsoon rainfall totals by analyzing multiple products created from different sources and methodologies, including simulations. We find that the representation of the regional structure of the monsoon rains is sensitive to the choice of rainfall product and that there is a strong regional dependence to this sensitivity, consistent with Cash et al. (2008b).

We also show, through analysis of simulations made as part of Project Athena (Kinter et al. 2013), that while the model integrations do not reproduce the observed time series of seasonal rainfall anomalies for the various regions, they reproduce the relationship between the regions to such a degree that they cannot be distinguished from the observational products. In this metric the simulations are comparable to, and can even outperform, some of the reanalysis products analyzed. Thus, we find that accurate representation of interannual variations and the regional structure of rainfall can be independent.
More surprisingly, at least in some instances an atmosphere-only model, forced with observed sea surface temperature but without assimilating atmospheric data, can outperform state-of-the-art reanalysis products.

\section{Data: Observations, reanalysis, and simulation}

As noted in the introduction, previous work has demonstrated that significant differences exist in published, research-quality rainfall products for the monsoon region, and that these differences are of sufficient magnitude that conclusions can potentially be sensitive to the choice of rainfall product (Cash et al. 2008b). Disagreement between products becomes more pronounced away from the extensive rain gauge network covering western and central India and closer to Bangladesh, Myanmar, and the Bay of Bengal. Even for a quantity as apparently straightforward as the sign of the June-August (JJA) anomaly, agreement between the five products examined in Cash et al. (2008b) fell from $70 \%$ to $80 \%$ over western and central India to $<50 \%$ over Bangladesh and Myanmar for the period 1979-2003 (see their Fig. 5).

To assess the potential sensitivity of our results to the choice of rainfall product, we consider multiple published rainfall data products for the period. For the purposes of this analysis, datasets were required to span at least $30 \mathrm{yr}$ and to include values over the ocean and land points outside of the political boundaries of India. These requirements preclude the use of certain high quality products, such as the land-only, India-only dataset maintained by the Indian Meteorological Department (and analyzed in Parthasarathy et al. 1996) and the relatively short Tropical Rainfall Measuring Mission (TRMM; Kummerow et al. 1998) dataset.

Of the products considered in our study, one is based purely on rain gauge data, namely, the Chen et al. (2002) dataset. While this dataset includes only land-based data in its analysis, values are produced and reported over a small number of ocean points, which are retained in our analysis. Two additional datasets, the Climate Prediction Center Merged Analysis of Precipitation (CMAP; Xie and Arkin 1996, 1997) and the Global Precipitation Climatology Project (GPCP v2.2; Adler et al. 2003), are merged satellite-gauge products.

We also analyze precipitation and circulation anomalies from three recent reanalysis products, which combine atmospheric observations with model-generated fields: the National Centers for Environmental Prediction (NCEP) Climate Forecast System Reanalysis version 2 (CFSRv2; Saha et al.2010), the National Aeronautics and Space Administration (NASA) Modern-Era Retrospective Analysis for Research and Applications (MERRA; 
Rienecker et al. 2011), and the European Centre for Medium-Range Weather Forecasts (ECMWF) Interim Re-Analysis (ERA-I; Dee et al. 2011).

In addition to the above observational products, we also consider circulation and precipitation anomalies from simulations made using the ECMWF Integrated Forecast System (IFS) forced with observed sea surface temperature (SST) as part of Project Athena [see Kinter et al. (2013) for model and project details] at an effective grid size of $16 \mathrm{~km}$ for the period 1960-2007. Note that while multiple resolutions and experimental configurations are available in the Athena catalog, the results presented here are not sensitive to those choices (not shown).

\section{Results}

We first consider the representation of the monsoon seasonal mean [June-September (JJAS)] rainfall and its variability in the three purely observational products [CMAP, GPCP, and Chen et al. (2002)]. Although the CMAP and GPCP products share many aspects of their input data and analysis methods (e.g., Yin et al. 2004), they still differ substantially in their representation of even these basic features of the monsoon. Mean JJAS rainfall in the CMAP (Fig. 1a) product is higher over the northern Bay of Bengal relative to GPCP (Fig. 1b), while in the GPCP product the highest values are concentrated along the coast of Myanmar. Compared to the gauge-only Chen product (Fig. 1c), both CMAP and GPCP show substantially lower rainfall over Bangladesh and the Western Ghats, as well as a less prominent rain shadow east of the Western Ghats. These differences potentially reflect the higher resolution of the Chen product $\left(0.5^{\circ}\right.$ versus $2.5^{\circ}$ for CMAP and GPCP). While all three products show maxima in variability along the coast of Myanmar, variability in the GPCP data (Fig. 1e) is substantially lower than in both the CMAP (Fig. 1d) and Chen (Fig. 1f) products. Variability in the CMAP data is significantly higher than in GPCP prior to 1994 in this region, after which variability in the two products is similar (not shown). Variability in the Chen product is higher than in both satellite products in this region and also remains relatively uniform throughout the period examined.

To simplify the comparison of the different regions and data products, we first calculate rainfall indices for each of our data products and regions of interest. We focus on four regions (see Fig. 1 for dimensions): the Western Ghats (WG), the Ganges basin (GB), the Bay of Bengal (BB), and Bangladesh (BD). Rainfall indices are calculated as area-averaged and linearly detrended anomalies for 1979-2009 (the IFS simulations end in 2007). Pearson's correlation coefficient is calculated between products for each of our four regions (Fig. 2), as well as between regions for each product (Fig. 3). Correlations between products (e.g., CMAP versus GPCP for the WG region; Fig. 2a) provide a measure of the uncertainty in the reported rainfall for these regions, while correlations between regions for the same product (e.g., WG versus GB in the MERRA product; Fig. 3a) provide an assessment of the regional structure of monsoon rainfall as represented by that product. The use of multiple products in the calculation of the regional structure in turn provides an assessment of the significance of the observational uncertainties on this quantity.

\section{a. Uncertainty in rainfall totals}

For the WG region, all of the observational products considered (gauge, merged satellite, and reanalysis) are reasonably well correlated, with most values above 0.6 and several products correlated at 0.8-0.9 (Fig. 2a). However, it is important to note that even in this closely observed region most correlations between products are significantly less than 1.0. The IFS simulations are not significantly correlated with the observed products in the WG, demonstrating that the simulation is not capturing the observed interannual variations of the monsoon rains in this region.

For the GB region (Fig. 2b), the gauge and merged satellite products (Chen, CMAP, and GPCP) are still highly correlated (roughly $0.8-0.9$ ), but correlations with and between the reanalysis products are substantially lower. Interestingly, while both CFSR and MERRA are reasonably well correlated with ERA-I, correlations between CFSR and MERRA are worse (0.2) than those of any other pair of products barring IFS. The IFS simulations are negatively correlated with all of the observed products, indicating a significant problem with the model's representation of year-to-year variations in rainfall for this region.

The general reduction in correlation strength continues into the BB (Fig. 2c) and BD regions (Fig. 2d) with correlations generally falling below 0.4 and 0.5 , respectively. The fact that correlations tend to be higher for BD than BB perhaps reflects the influence of the limited but nonzero number of rain gauge observations for $\mathrm{BD}$ included in the various datasets. The $\mathrm{BB}$ region as defined here is also influenced by values along the coast of Myanmar, which is a particularly data-poor, high-variability region (Cash et al. 2008b). The IFS simulations remain an outlier for these regions and this metric. However, they are much less noticeably so, particularly for the BB region, because of the overall decline in correlation strength compared to WG and GB. 


\section{9-2009 JJAS Mean Rainfall}

(a) CMAP

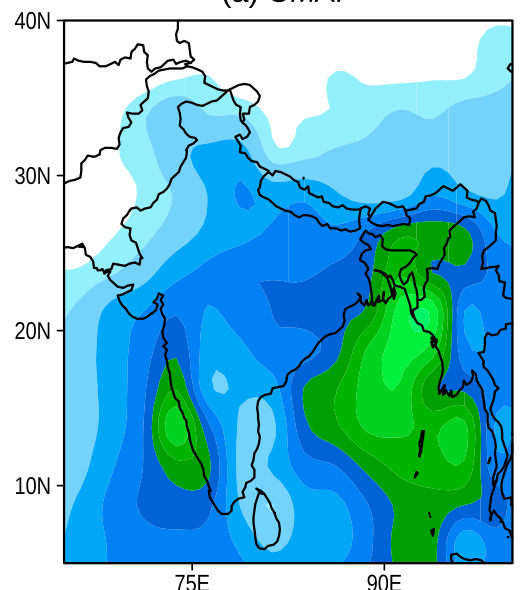

(b) GPCP

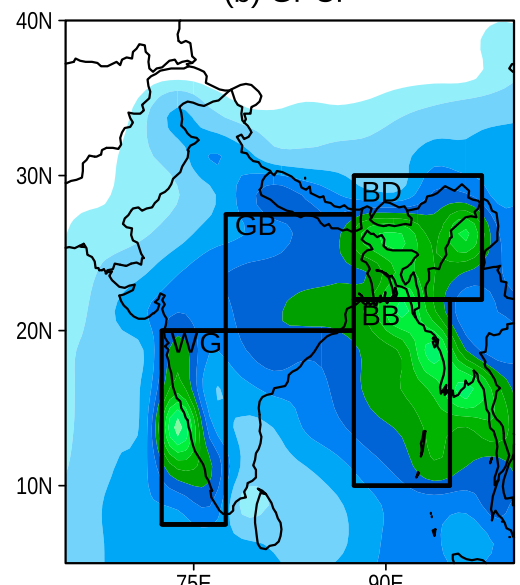

(c) Chen et al.

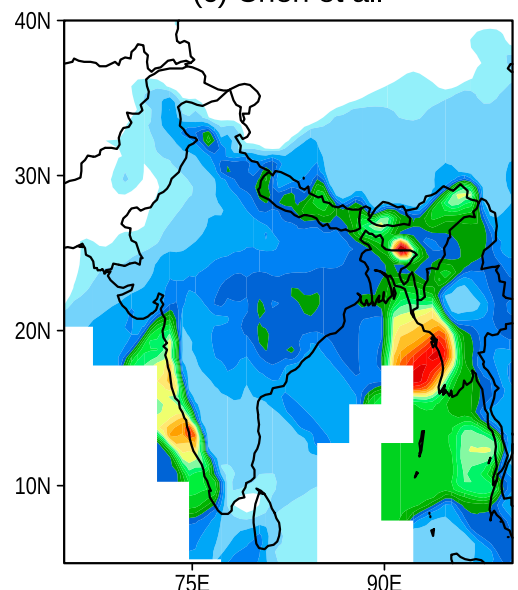

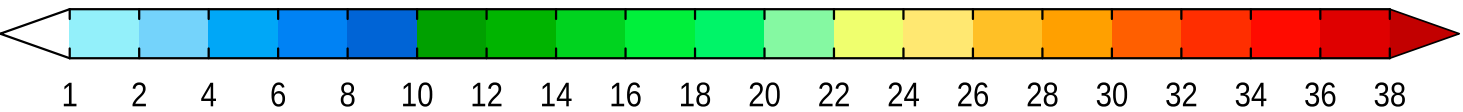

\section{9-2009 JJAS Rainfall Standard Deviation}

(d) CMAP

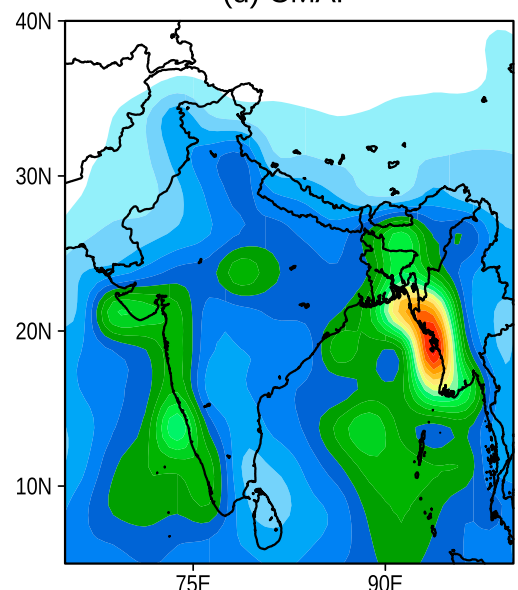

(e) GPCP

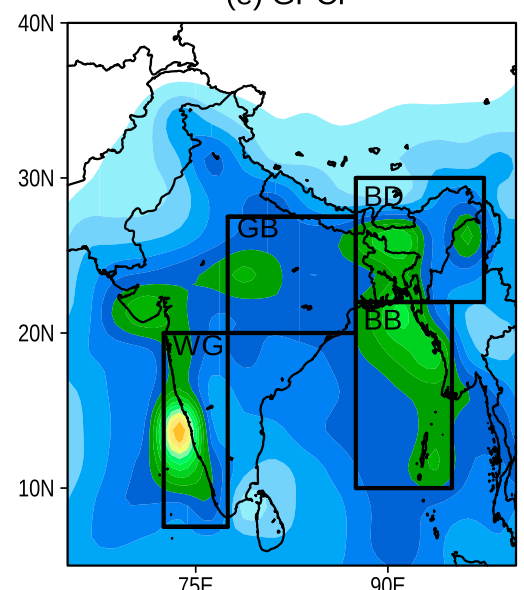

(f) Chen et al.

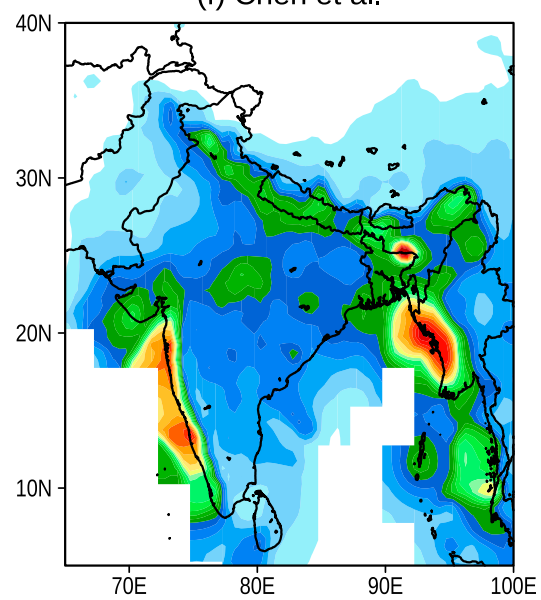

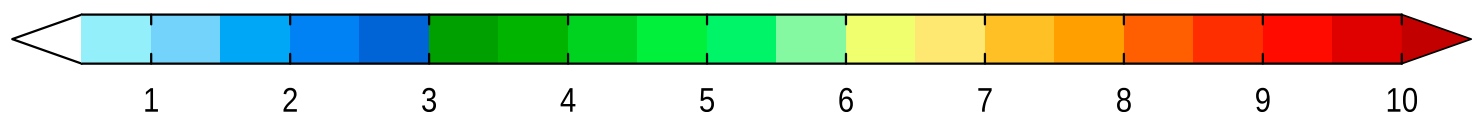

FIG. 1. (a)-(c) JJAS mean rainfall (mm day ${ }^{-1}$ ) from CMAP, GPCP, and Chen et al. (2002) rainfall products, respectively and (d)-(f) its standard deviation, respectively. Boxes in (b) and (e) denote regions used to define rainfall indices described in the text.

Somewhat surprisingly, despite the overall similarities in the CMAP and GPCP products, for the BD region they are generally better correlated with the reanalysis products than they are with each other. This is likely due to differences in their representation of variability along the coast of Myanmar, as discussed both in Fig. 1 and described in greater detail below.

\section{b. Uncertainty in rainfall structure}

Turning our focus now to the representation of regional rainfall structure in the different products, we find that WG rainfall is not significantly correlated with GB and BD rainfall in all products, except CFSR (Fig. 3a), and is not significantly correlated with $\mathrm{BB}$ rainfall in all 

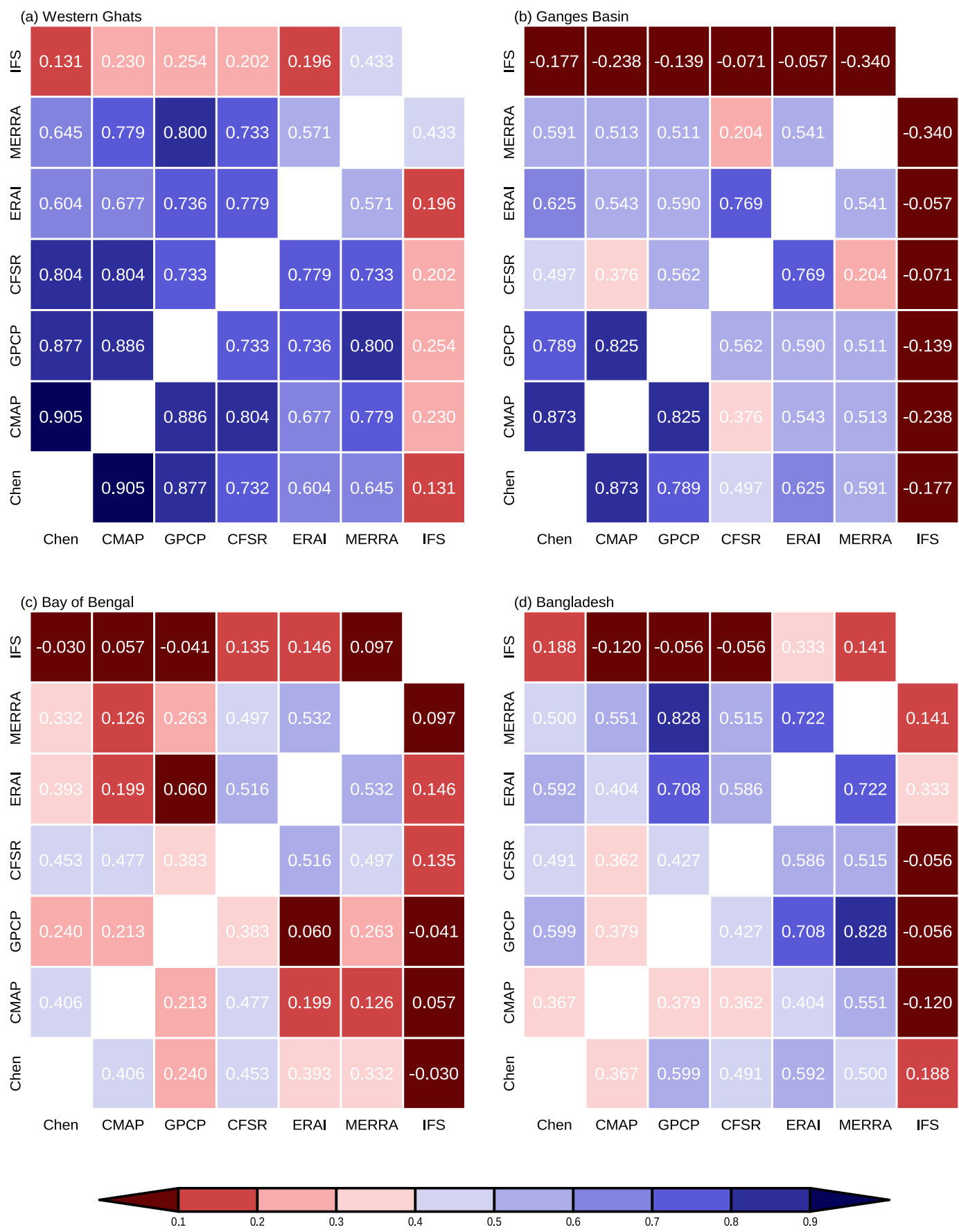

FIG. 2. Correlation between regional indices calculated from different rainfall products for (a) WG, (b) GB, (c) BB, and (d) BD. Note the transition from relatively good agreement (blue shades) between products for (a) and (b) to generally poor agreement (red shades) for (c) and (d). Magnitudes $>0.31$ are significant at the $90 \%$ level.

products except ERA-I and Chen. Thus, on balance, WG rainfall is independent of rainfall in the other three regions, although the different products are not unanimous on this point.

Remarkably, the IFS simulations are not outliers in this metric and show no significant correlations between the three regions. The IFS values are not significantly different from the various observed products, with the exception of CFSR. Thus, despite the inability of the IFS simulations to reproduce the observed interannual variability as described above, the relationship between the WG and the other regions is reproduced to within the 

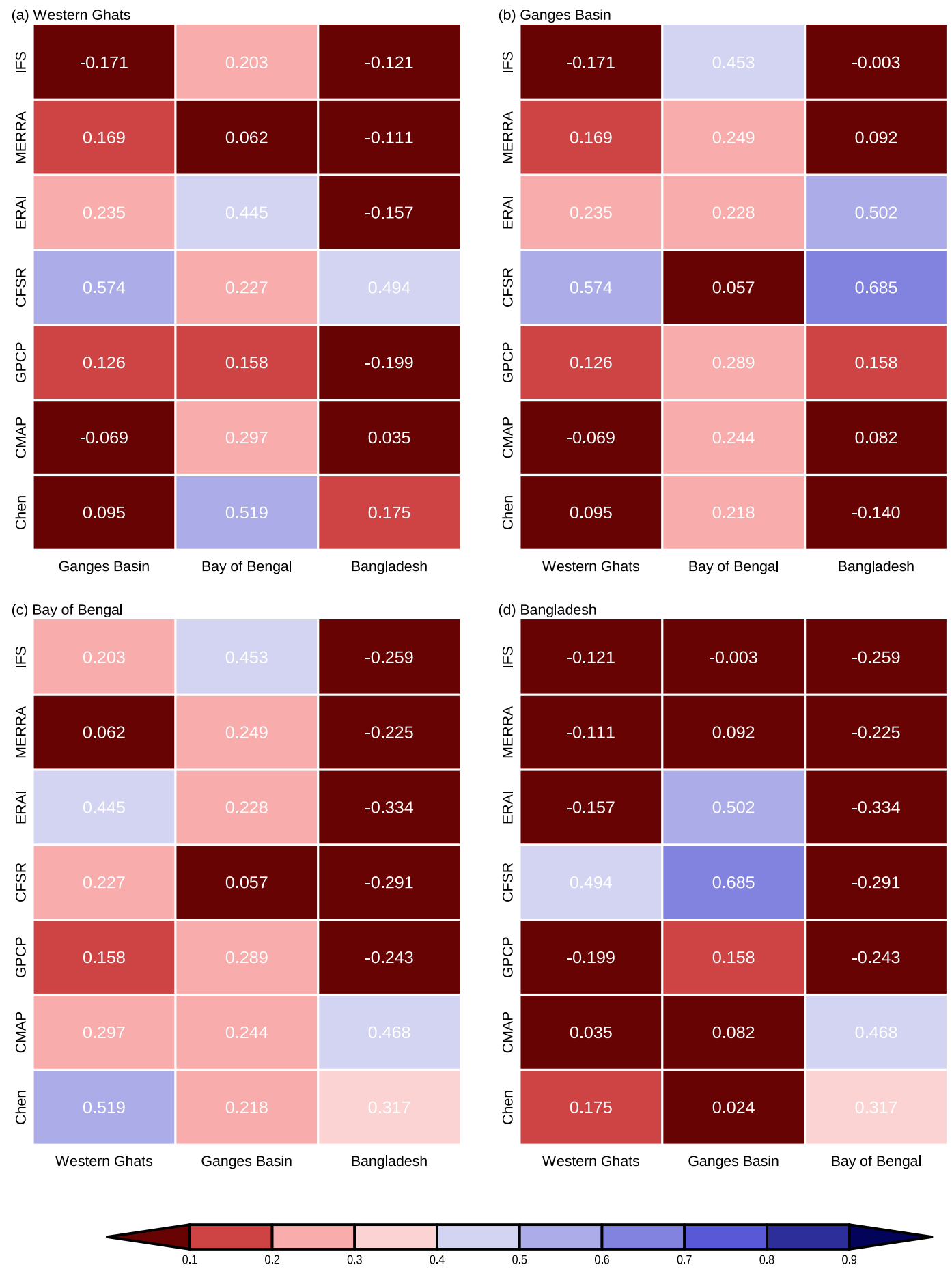

FIG. 3. Correlation between different regions as represented by different rainfall products for (a) WG, (b) GB, (c) BB, and (d) BD. Regions are listed along the horizontal axis and products are shown along the vertical. Magnitudes $>0.31$ are significant at the $90 \%$ level.

degree of uncertainty represented by the multiple observed products.

As with the WG region, the majority of the products show no significant correlation between GB rainfall and rainfall in the other regions (Fig. 3b). CFSR remains an outlier for this region and, along with ERA-I, indicates a strong positive relationship between $\mathrm{GB}$ and $\mathrm{BD}$ rainfall that is not reproduced by the other products. In 
(a) CMAP BD JJAS Correlation

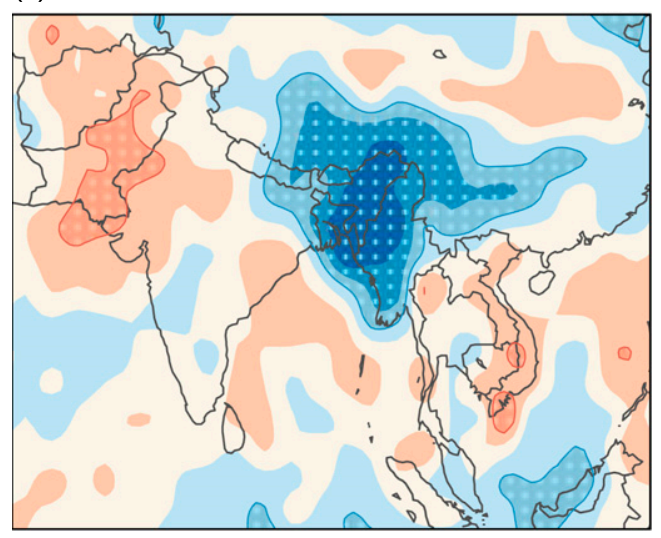

(b) GPCP BD JJAS Correlation

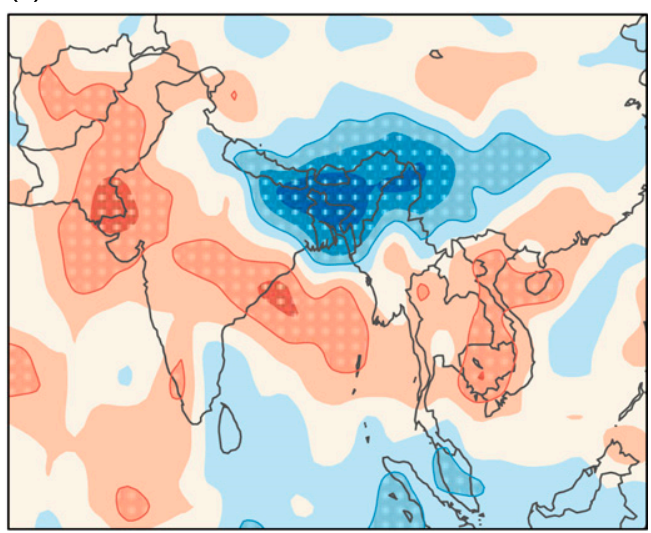

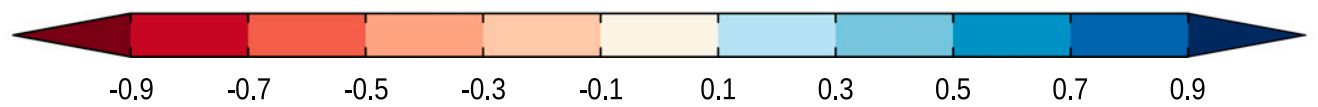

FIG. 4. Correlation of (a) CMAP and (b) GPCP BD rainfall index against JJAS rainfall. Stippling denotes significance at the $90 \%$ level.

contrast, the values for the MERRA data are not significantly different from those of the Chen-CMAPGPCP products. The IFS simulations show a somewhat stronger relationship between $\mathrm{GB}$ and $\mathrm{BB}$ than the other products, although only the difference with CFSR is statistically significant. Correlations between the BD and $\mathrm{BB}$ regions (Figs. 3c,d) are similar in strength and sign (negative) for all products with the exception of Chen and CMAP.

Although we do find differences between the products in their assessment of regional rainfall structure, the conclusion that rainfall in the four regions is not significantly correlated is generally insensitive to the choice of data product. However, there are two notable exceptions. One is the aforementioned issue with the CFSR data, which suggests a strong association between all regions except for $\mathrm{BB}$ that is not seen in the other data products. The second is the association between the $\mathrm{BD}$ and $\mathrm{BB}$ regions, in which even the sign is notably dependent on the choice of product. The Chen and CMAP data place the correlation in the range of 0.3 to 0.5 , while the range in the other products is from -0.2 to -0.3 . While the Chen data cannot be given great weight over the BB (values are generally either missing or purely a product of the gridding scheme), the disagreement between GPCP and CMAP in particular warrants further investigation.

Regressing the BD index and rainfall at all other points within the monsoon region, we find that in the CMAP product (Fig. 4a) BD rainfall extends southward along coastal Myanmar, and hence the $\mathrm{BD}$ and $\mathrm{BB}$ indices are positively correlated. In contrast, the same calculation using the GPCP product (Fig. 4b) shows BD rainfall as separate from the $\mathrm{BB}$ result and weakly negatively correlated. However, if the analysis period is limited to 1995 onward, thus after the change in CMAP variability in this region noted in the discussion of Fig. 1, both CMAP and GPCP show negative correlations between BD and BB (not shown). Combined with the fact that neither the IFS simulations nor any of the reanalysis products show a positive correlation between these two regions, it seems likely that the GPCP representation of the relationship between $\mathrm{BD}$ and $\mathrm{BB}$ is the more accurate one.

\section{c. Regional rainfall patterns}

When we expand our analysis of rainfall patterns associated with the regional rainfall indices to include all products and regions, interesting features emerge. In the GPCP product, rainfall over the WG region is associated with a broad region of enhanced rainfall stretching into northwestern India and Pakistan, and decreased rainfall over northeastern India and Myanmar (Fig. 5a). Rainfall over the GB region shows weak negative correlations with Bangladesh and positive correlations with northeastern (NE) India, and is strongly associated with reduced rainfall over the Indian Ocean to the south of India (Fig. 5b). Similar patterns hold for BD and BB rainfall (Figs. 5c and 5d, respectively). For each region a band of anomalous rainfall stretches southeast-northwest from the coast of Myanmar to northwestern India, while anomalies of the opposite sign are centered over Bangladesh. The precise locations, extents, and magnitudes of the rainfall centers differ among the four patterns, leading 
(a) Western Ghats

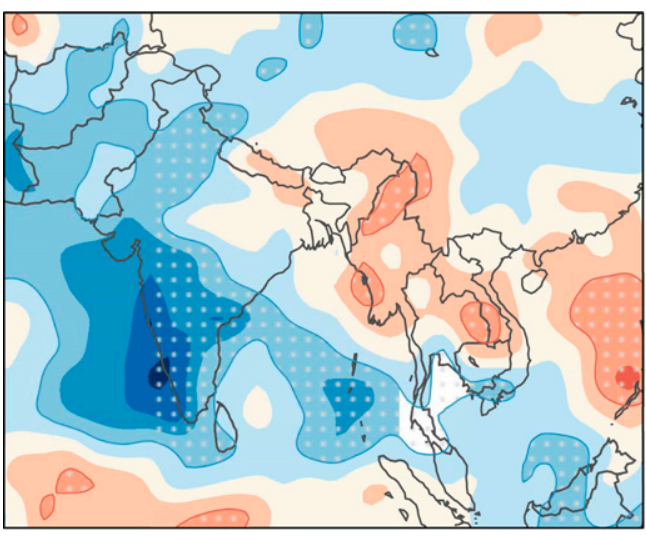

(c) Bay of Bengal

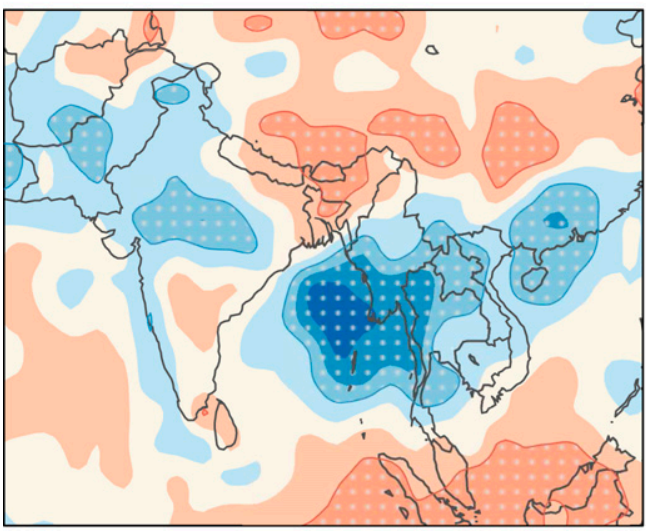

(b) Ganges Basin

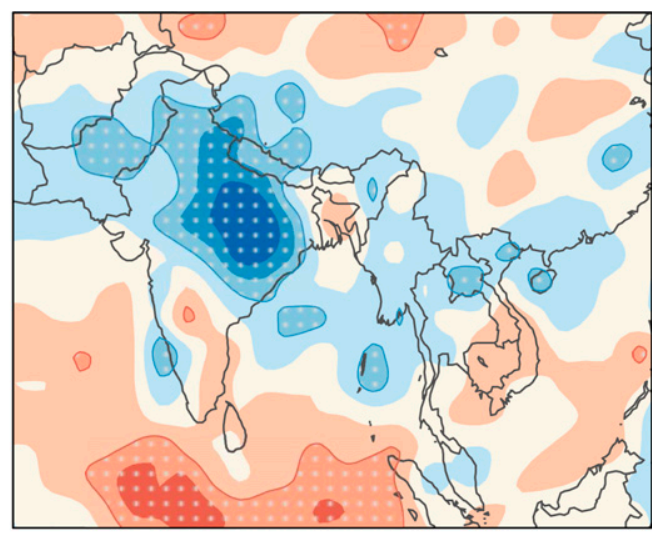

(d) Bangladesh

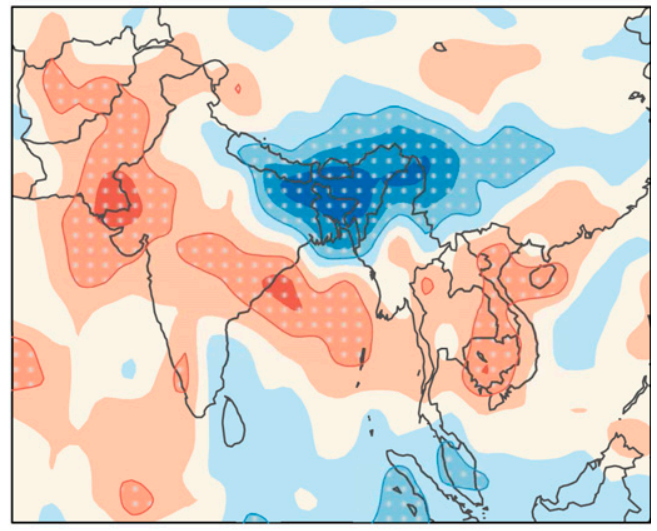

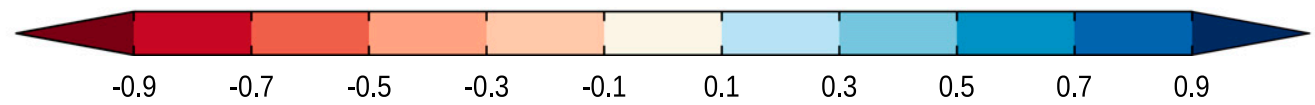

FIG. 5. Regional structure of monsoon rainfall in GPCP, as represented by correlation between rainfall indices for (a) WG, (b) GB, (c) BB, and (d) BD and rainfall at every other point. Stippling denotes values significant at the $90 \%$ level.

to the low correlations shown in Fig. 3. Correlation patterns calculated from the CMAP product (not shown) are similar to those found for GPCP, with the exception of the differences in BD-BB rainfall noted above. We do not calculate correlation patterns for the Chen data, as the ocean values in this product are either missing or entirely a product of the optimal interpolation scheme.

While GPCP and CMAP are reasonably similar in their rainfall patterns, there are wide differences among the reanalysis products. As suggested by the index analysis (Fig. 3), the structure of the rainfall correlation patterns in CFSR (Fig. 6) differs substantially from GPCP (Fig. 5). Statistically significant positive correlations extend over a broad area for all four regions, most prominently over land, such that positive rainfall anomalies in one region tend to represent a local enhancement of a region-wide increase in rainfall. The negative correlation between western-central India and Bangladesh-northeastern India in particular is absent. This problem is not unique to CFSR, as the same calculation performed using ERA-I yields very similar patterns (not shown), including the overly strong correlations between India and Bangladesh.

In contrast, the precipitation patterns calculated from MERRA (Fig. 7) are essentially indistinguishable from the GPCP patterns (Fig. 5) and CMAP (outside of the BD-BB correlation). The four regions are clearly separated, including the sharp distinction between Bangladesh and western-central India. Representation of the hydrological cycle was a specific point of emphasis for MERRA (Rienecker et al. 2011), which may explain its improved fidelity in this metric relative to CFSR and ERA-I.

As anticipated by the results of the index comparison (Fig. 3), the IFS rainfall correlation patterns (Fig. 8) 


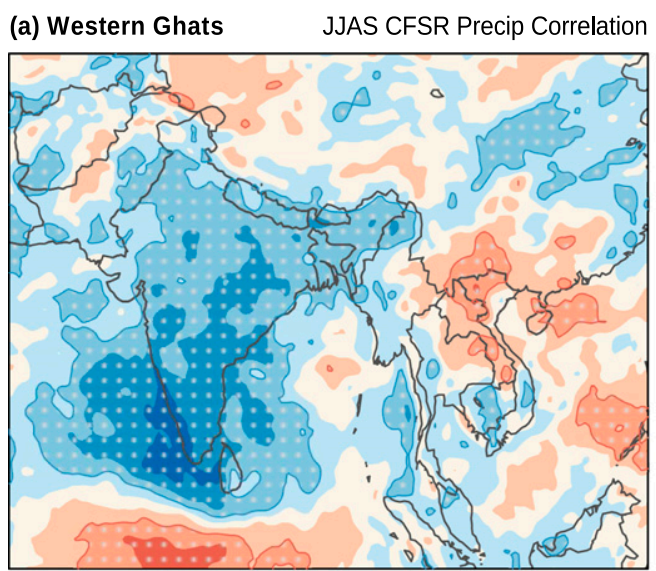

(c) Bay of Bengal JJAS CFSR Precip Correlation

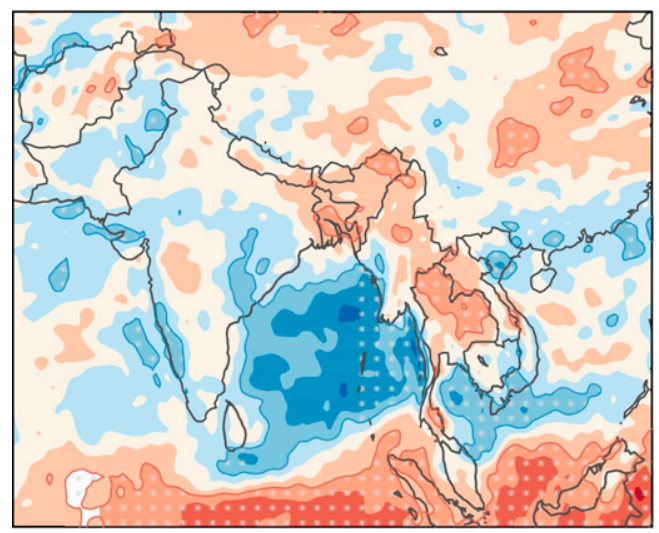

(b) Ganges Basin

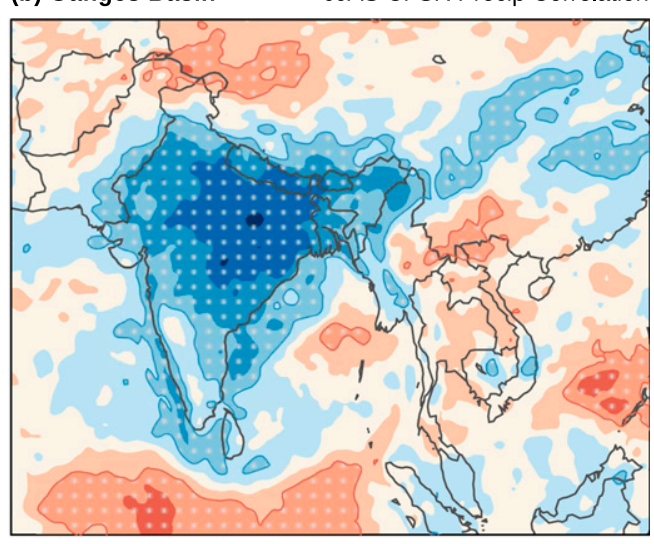

(d) Bangladesh

JJAS CFSR Precip Correlation

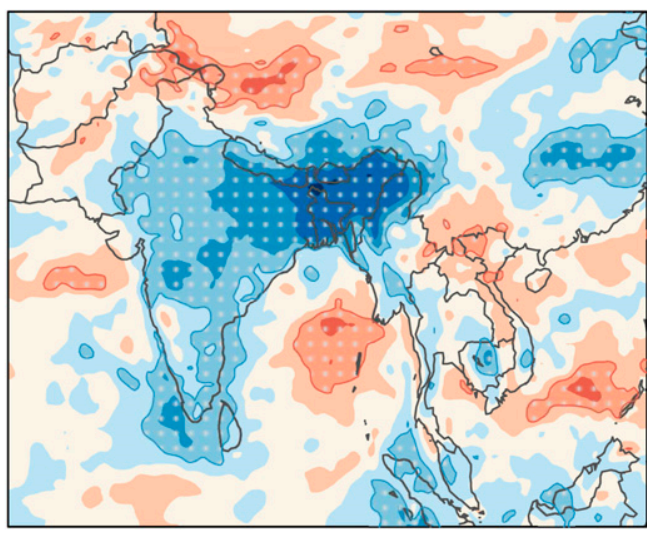

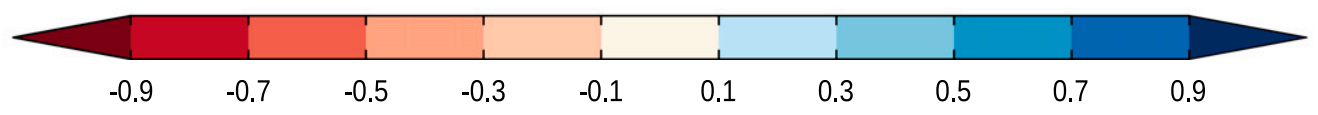

FIG. 6. As in Fig. 5, but for regional structure of monsoon rainfall in CFSR.

strongly resemble the GPCP-CMAP-MERRA patterns. The only exception is in the relationship between the GB and BB regions, where the IFS GB center of action extends too far into the Bay of Bengal relative to the other products. This leads to the unusual situation in which model simulations, made using no atmospheric observations, provide a closer match to the observations than two of the three reanalysis products considered (CFSR and ERA-I).

\section{d. Regional circulation patterns}

While the reanalysis products differ in their representation of precipitation, it is not clear if those differences are in precipitation alone, or if they are in turn being driven by differences in their representations of the seasonal monsoon circulation. Similarly, while the IFS simulations reproduce the observed structure of ISM rainfall anomalies, they may not do so in a dynamically consistent fashion.
To address these questions, we regress the $850-\mathrm{mb}$ circulation against the different precipitation indices for each region and product. In MERRA, WG rainfall is characterized by onshore flow at $850 \mathrm{mb}(1 \mathrm{mb}=1 \mathrm{hPa})$ from the southwest in the southern part of the Western Ghats, from the south-southeast across the northern reaches of the range, and southerly flow onshore from the northwest Bay of Bengal (Fig. 9a). Enhanced GB and $\mathrm{BB}$ rainfall trends are both associated with a cyclonic circulation pattern centered near $20^{\circ} \mathrm{N}, 85^{\circ} \mathrm{E}$, with slight differences in the location of maximum winds and curvature (Figs. 9b and 9c, respectively). BD rainfall, in contrast, is associated with an anticyclonic circulation pattern centered near the same area (Fig. 9d) and westerly anomalies along the foothills of the Tibetan Plateau.

The association between BD rainfall with anomalous westerlies, as opposed to easterlies, along the foothills of the Tibetan Plateau provides a dynamical 
(a) Western Ghats

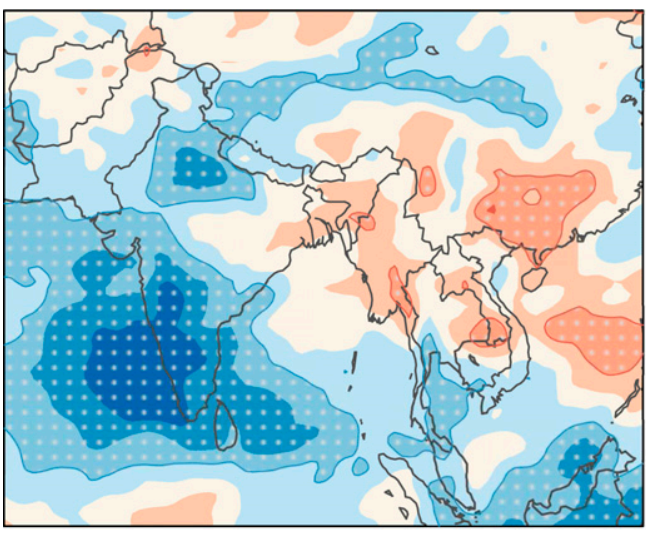

(c) Bay of Bengal

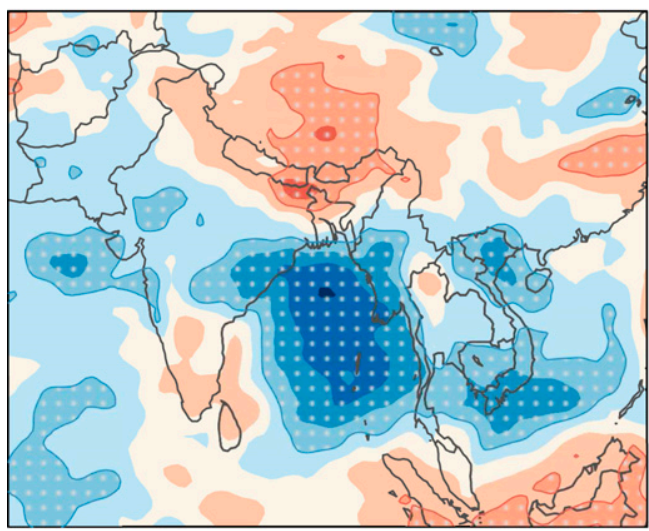

(b) Ganges Basin JJAS MERRA Precip Correlation

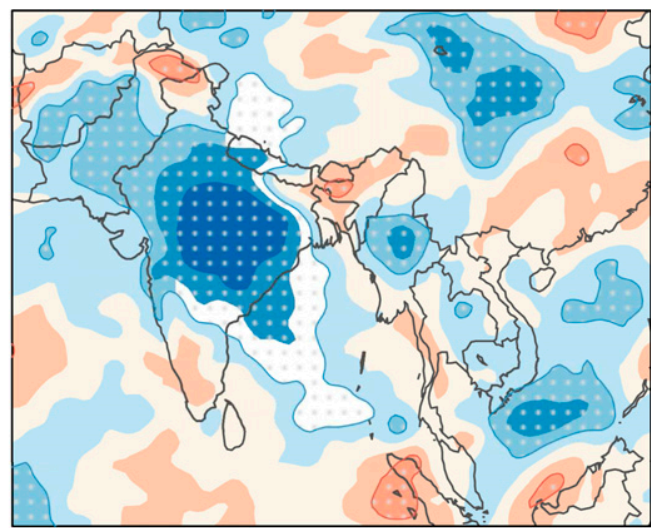

(d) Bangladesh

JJAS MERRA Precip Correlation

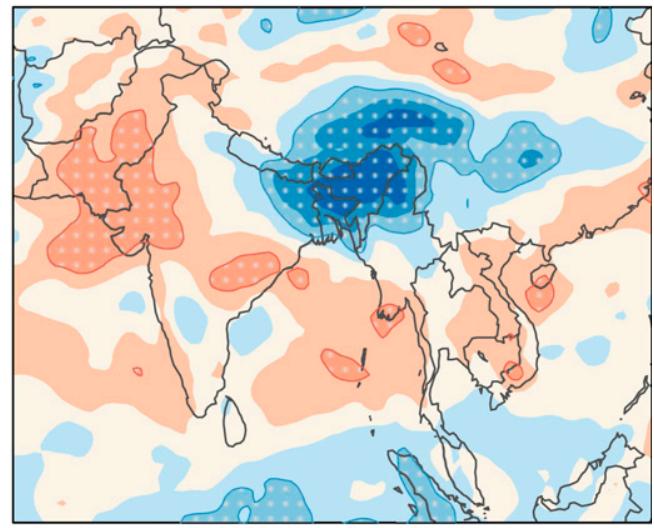

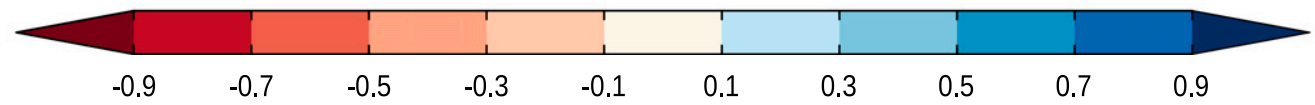

FIG. 7. As in Fig. 5, but for regional structure of monsoon rainfall in MERRA.

explanation for the weak (nonsignificant) negative correlation between the northeast region and the majority of the other regions noted for the IMD in Parthasarathy et al. (1996) and the majority of products in Fig. 3d. This association between Bangladeshi rainfall and a change in the large-scale monsoon circulation also helps to explain why, despite the fact that precipitation in the BD region is of the small scale and noisy type es that GCMs traditionally struggle to represent, the association between BD rainfall and remote forcing by tropical SST anomalies can be captured by GCMs (e.g., Cash et al. 2008b).

Consistent with the results of the correlation analysis, the 850-mb circulation data from MERRA are closely reproduced by the IFS integrations (Fig. 10) but not by CFSR (Fig. 11). The eastward flow along the southern edge of the Tibetan Plateau associated with increased Bangladeshi rainfall is particularly well represented in IFS, although the flow across central India and into the
Bay of Bengal associated with GB rainfall is significantly increased. In contrast to MERRA and IFS, BD rainfall in CFSR (and ERA-I; not shown) is associated most strongly with onshore flow from the Bay of Bengal, rather than the flow to the southeast along the foothills seen in MERRA and IFS.

To address the question of whether the differences in CFSR-ERA-I and MERRA-IFS are due to the respective representations of precipitation or circulation, we repeat the regression analysis for CFSR, but with GPCP used in place of the CFSR precipitation. In this case a pattern similar to those of MERRA and IFS emerges (Fig. 12). The circulation pattern associated with BD rainfall in particular is greatly improved, as the relative strength of the onshore flow from the Bay of Bengal is reduced and the flow along the Tibetan Plateau emerges. Thus, it appears that the 850 -mb circulation is reasonably well constrained and consistent with observed precipitation for both CFSR-ERA-I and 
(a) Western Ghats JJAS IFS T1279 Precip Correlation

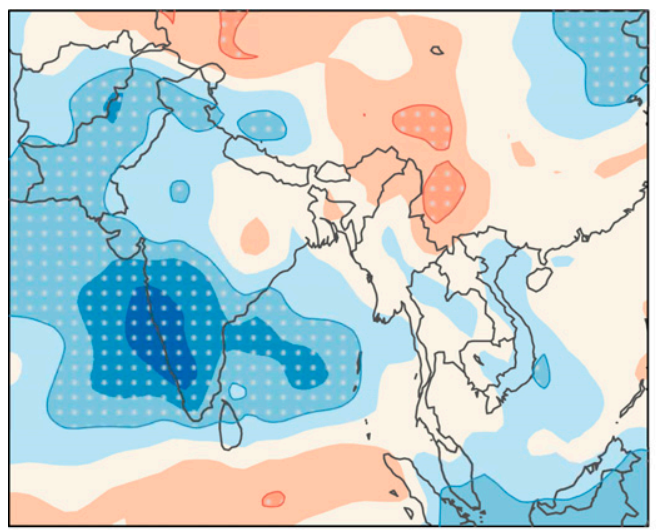

(c) Bay of Bengal JJAS IFS T1279 Precip Correlation

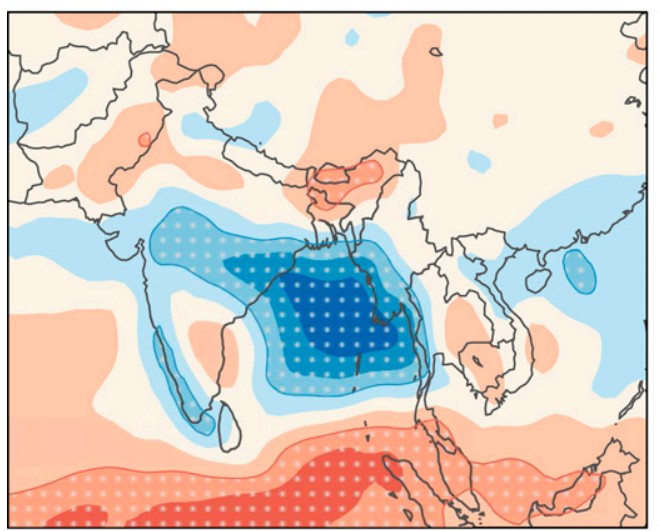

(b) Ganges Basin JJAS IFS T1279 Precip Correlation

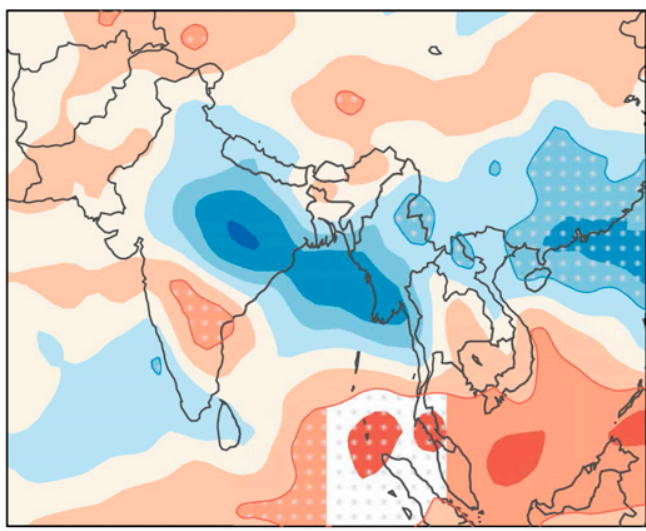

(d) Bangladesh

JJAS IFS T1279 Precip Correlation

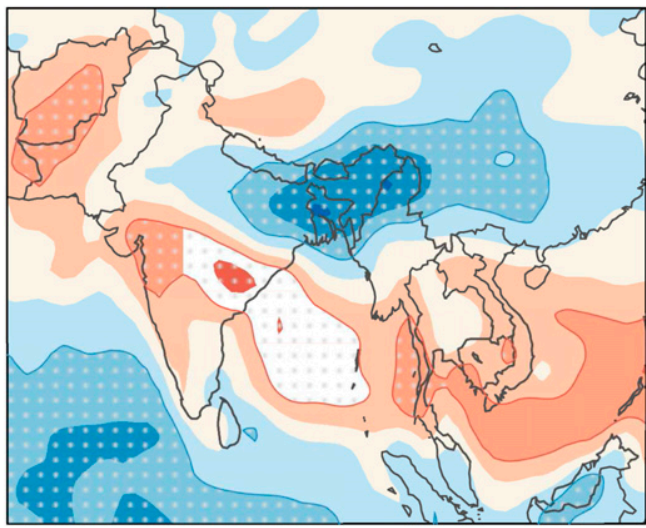

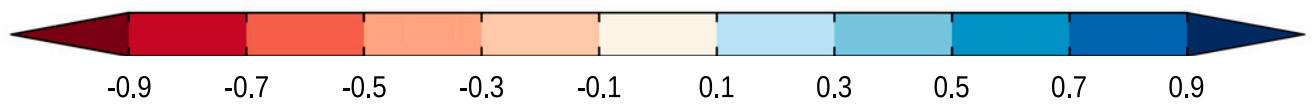

FIG. 8. As in Fig. 5, but for regional structure of monsoon rainfall in IFS.

MERRA and it is the reanalyzed precipitation that differs between the two products and leads to the differences in association with circulation. Given that MERRA precipitation more closely resembles the observed products, it then seems reasonable to conclude that the association in MERRA is the more accurate. Likewise, the similarity between the IFS and MERRA circulation patterns, particularly for the $\mathrm{WG}, \mathrm{BB}$, and $\mathrm{BD}$ regions, indicates that the model is correctly reproducing the observed link between precipitation and circulation for these regions.

\section{e. Association between rainfall and SST}

The differences between the rainfall products described above ultimately translate to differences in the diagnosed association between regional rainfall and remote SST, as shown by the regression between rainfall and SST for each product (Fig. 13). For the CMAP and GPCP data we use the Hadley Centre Global Sea Ice and Sea Surface Temperature dataset version 1.1
(HadISST1.1; Rayner et al. 2003), and for the CFSR, MERRA, and IFS we use their own associated SSTs. While GB rainfall is associated with cold SST in the eastern tropical Pacific in the CMAP, GPCP, and MERRA products (Figs. 13a, 13c, and 13g, respectively), the strength of the association decreases notably from MERRA to CMAP to GPCP. Rainfall in the CFSR product (Fig. 13e) is associated not only with negative SST anomalies in the eastern tropical Pacific, but also with positive anomalies in the western and central tropical Pacific "horseshoe." This pattern is strongly suggestive of a negative association with $\mathrm{El}$ Niño, an association that is also indicated by the other observed products to greater or lesser degree. Only IFS shows a positive association between GB rainfall and tropical Pacific SST (Fig. 13i). The model apparently misrepresents the teleconnection between the eastern tropical Pacific Ocean and Ganges basin rainfall, which, given that the model uses prescribed SST, may lie at the 
(a) Western Ghats

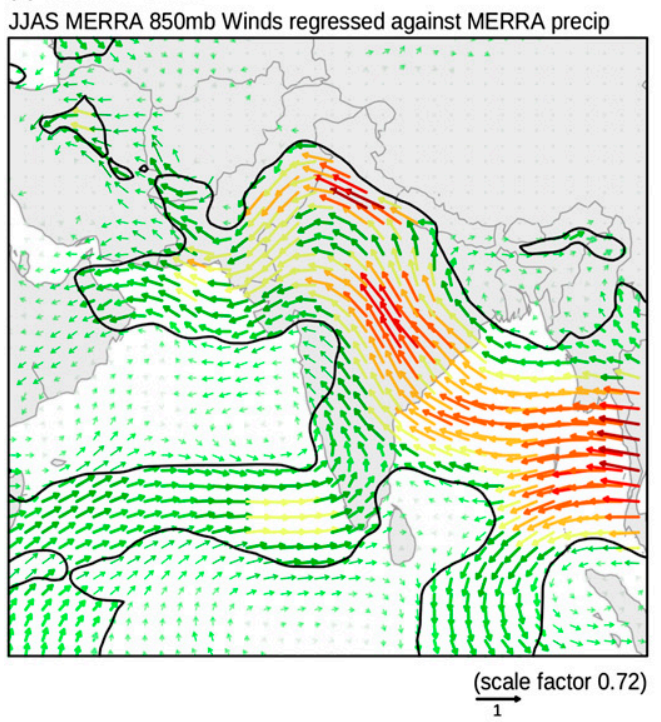

(c) Bay of Bengal

JJAS MERRA 850mb Winds regressed against MERRA precip

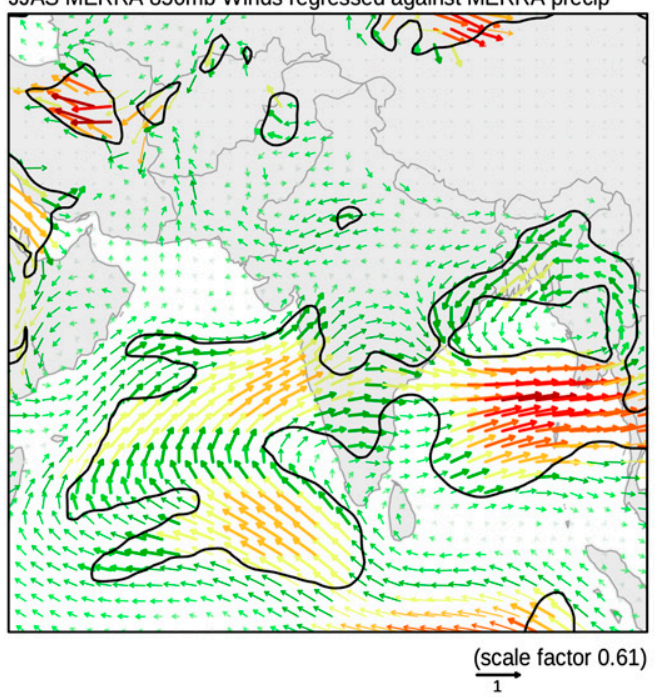

(b) Ganges Basin

JJAS MERRA 850mb Winds regressed against MERRA precip

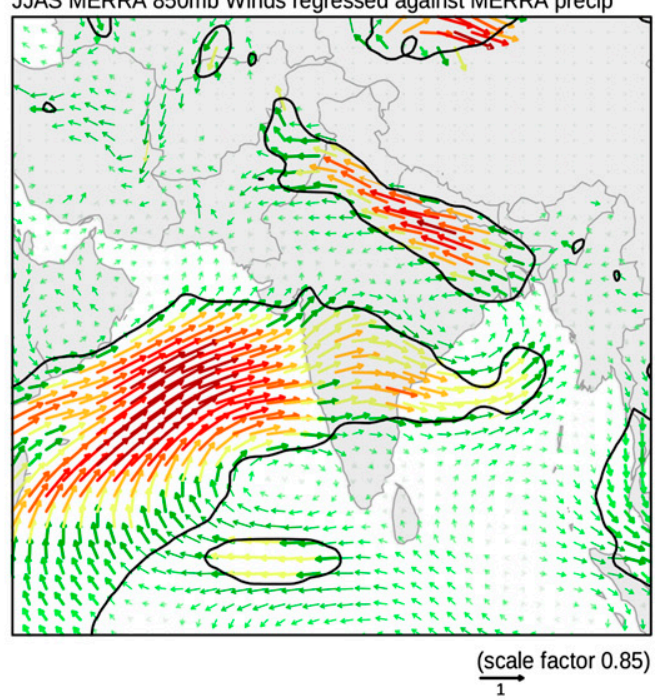

(d) Bangladesh

JJAS MERRA 850mb Winds regressed against MERRA precip

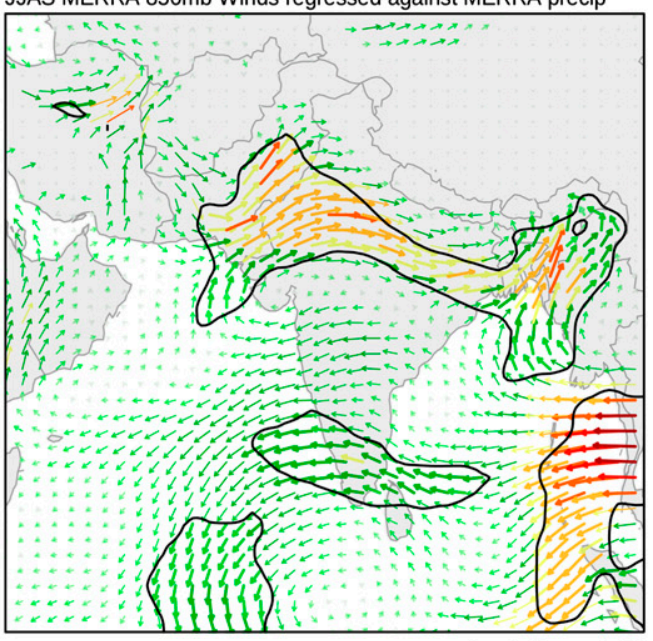

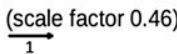

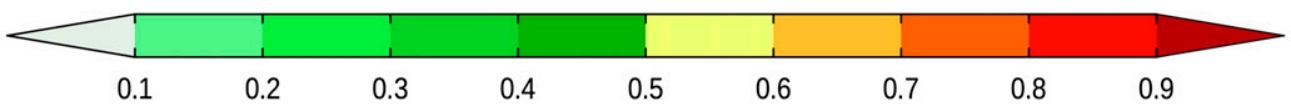

FIG. 9. The 850-mb winds from MERRA regressed on MERRA rainfall indices for (a) WG, (b) GB, (c) BB, and (d) BD. Color denotes magnitude of wind anomaly. Note that each panel is scaled to produce magnitudes of $0-1$ for comparison purposes; multiply values by the scale factor for each panel to recover actual magnitudes $\left(\mathrm{m} \mathrm{s}^{-1}\right)$. Contours and thicker vectors denote values significant at the $90 \%$ level.

root of its inability to reproduce the observed time series of seasonal rainfall anomalies (Fig. 2).

In contrast to the GB region, the association between $\mathrm{BD}$ and SST is relatively weak everywhere outside of the tropical South Atlantic (see Figs. 13b,d,f,h,j) for all products with the exception of CFSR. The strength of the association again varies from product to product, being strongest in CFSR (Fig. 13h) and weakest in GPCP and IFS (Figs. 13d and 13j, respectively). CFSR also shows the same strong association between BD rainfall and tropical Pacific SST as it does for GB rainfall, consistent with the overly broad correlation patterns seen in Fig. 6. As suggested by the correlation among rainfall indices for this region (Figs. 2 and 3), IFS is less of an outlier for BD 
(a) Western Ghats

JJAS IFS $850 \mathrm{mb}$ Winds regressed against IFS precip

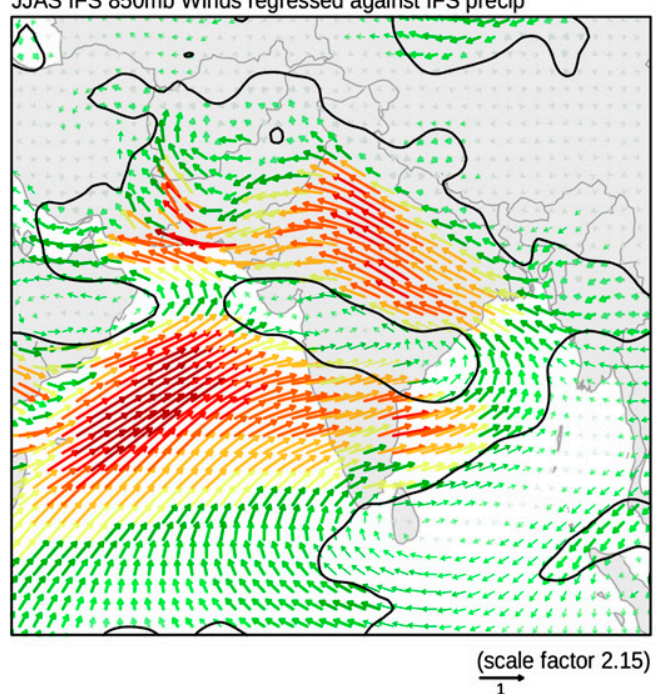

(c) Bay of Bengal

JJAS IFS $850 \mathrm{mb}$ Winds regressed against IFS precip

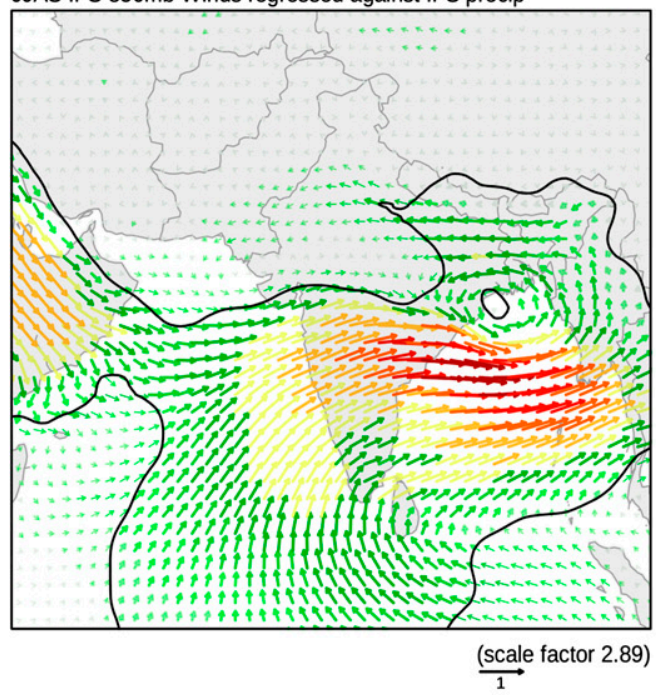

(b) Ganges Basin

JJAS IFS $850 \mathrm{mb}$ Winds regressed against IFS precip

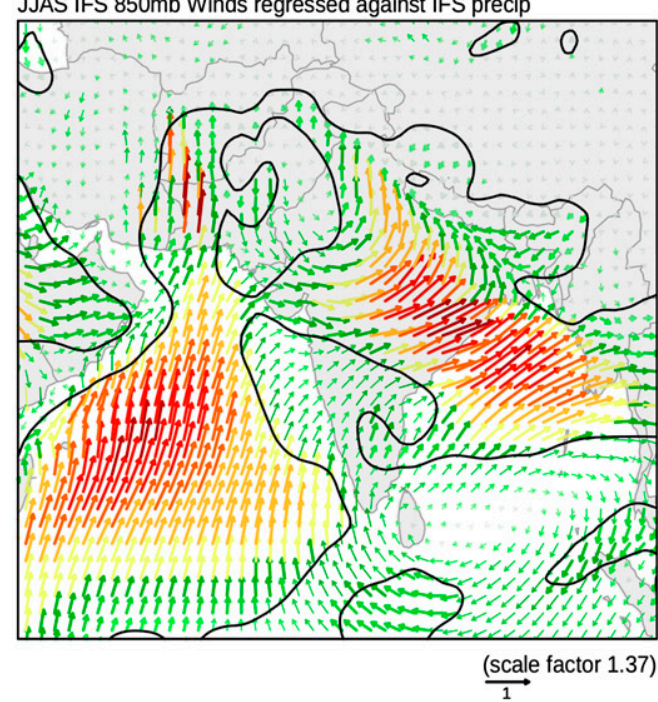

(d) Bangladesh

JJAS IFS $850 \mathrm{mb}$ Winds regressed against IFS precip

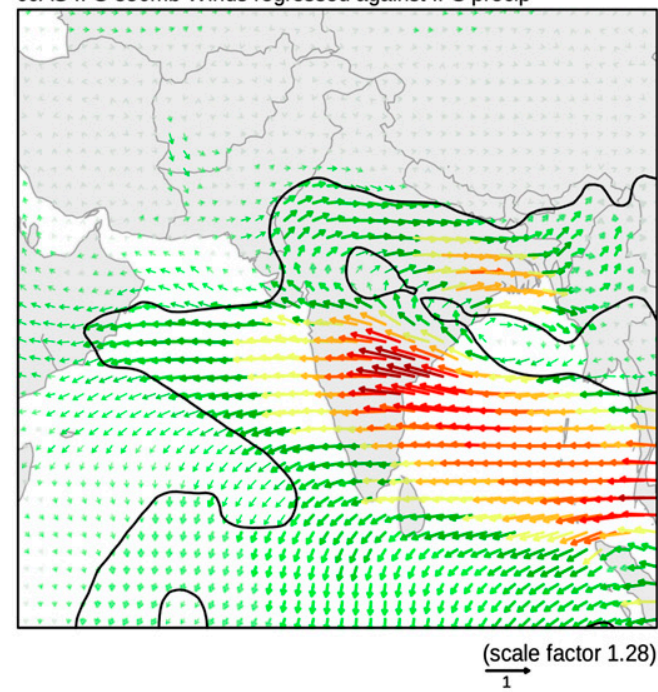

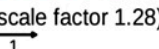

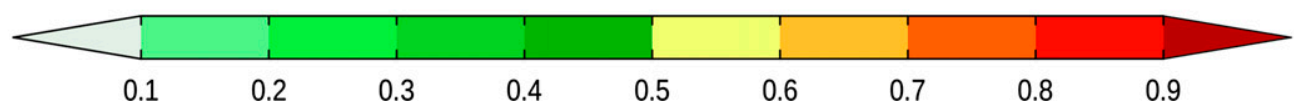

FIG. 10. As in Fig. 9, but for the 850 -mb winds from IFS simulations regressed on IFS rainfall indices.

rainfall than for GB and actually captures (albeit very weakly) the association with the tropical Atlantic and North Pacific seen in the observed products.

\section{Summary and conclusions}

In this work, we expand upon previous studies of regional variations in summer monsoon rainfall over the Indian subcontinent, both by extending the analysis domain to include regions outside the political boundaries of India and by considering multiple rainfall products simultaneously. We find that the four subregions analyzed, namely the Western Ghats, the Ganges basin, Bangladesh-NE India, and the Bay of Bengal, all exhibit high rainfall totals and low shared variance during the summer monsoon season. We also demonstrate through the analysis of multiple published rainfall products that, despite years of intensive observation and analysis, considerable uncertainty remains as to both the magnitude and distribution of Indian summer monsoon rainfall. Of the four regions considered, only for the Western Ghats do we find a consistent level of 
(a) Western Ghats

JJAS CFSR $850 \mathrm{mb}$ Winds regressed against CFSR precip

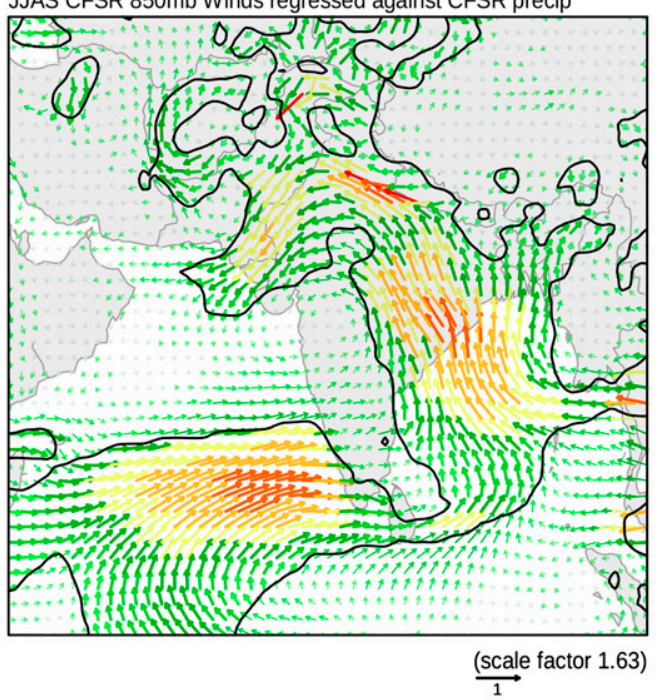

(c) Bay of Bengal

JJAS CFSR $850 \mathrm{mb}$ Winds regressed against CFSR precip

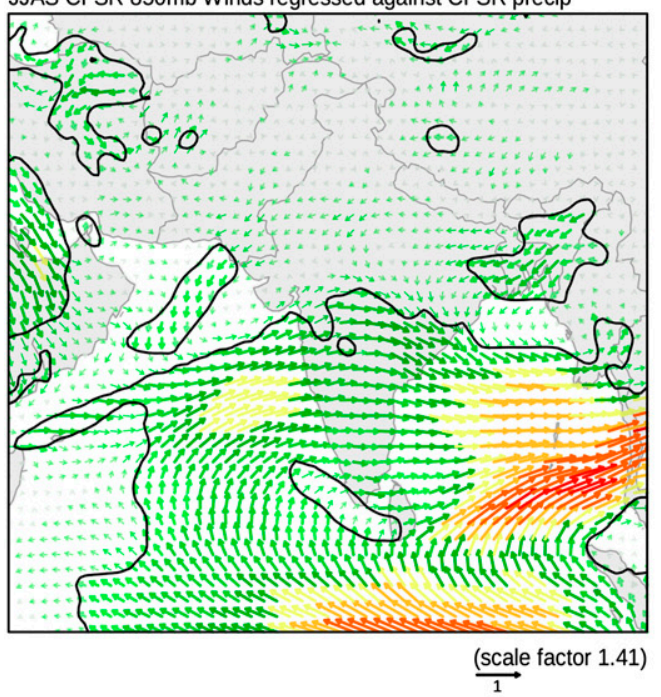

(b) Ganges Basin

JJAS CFSR $850 \mathrm{mb}$ Winds regressed against CFSR precip

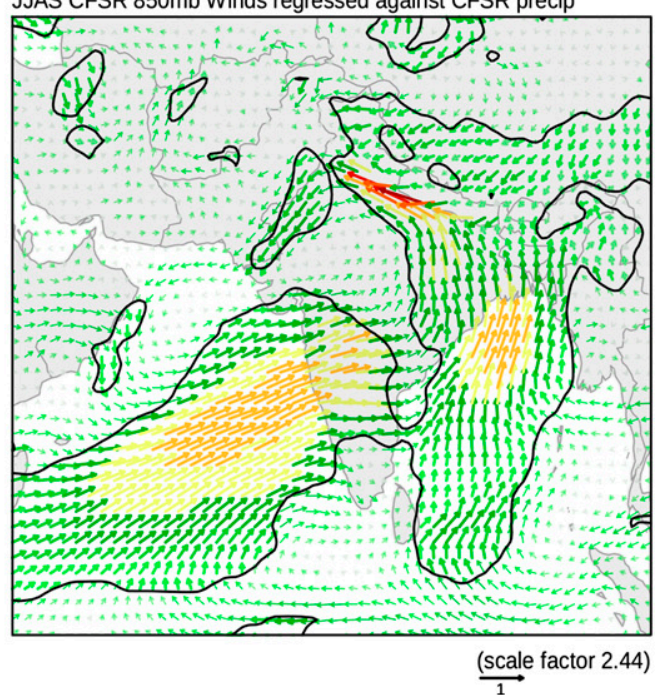

(d) Bangladesh

JJAS CFSR $850 \mathrm{mb}$ Winds regressed against CFSR precip

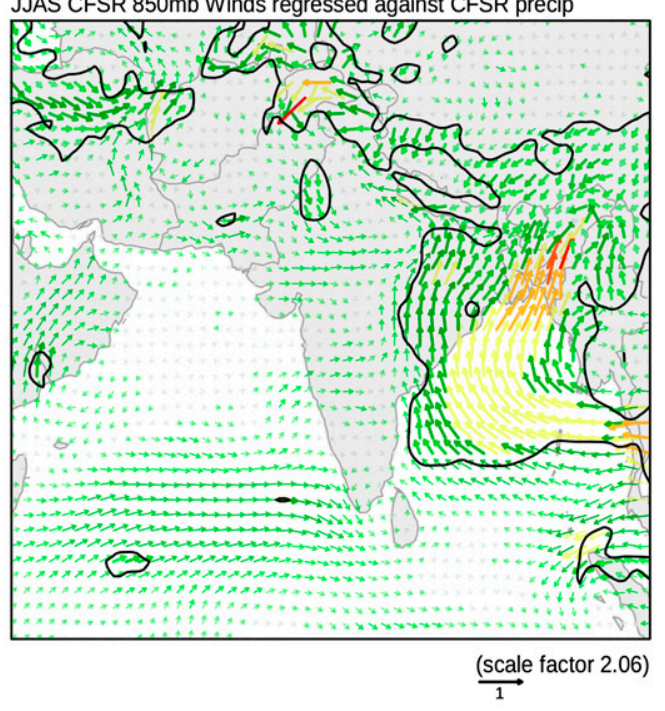

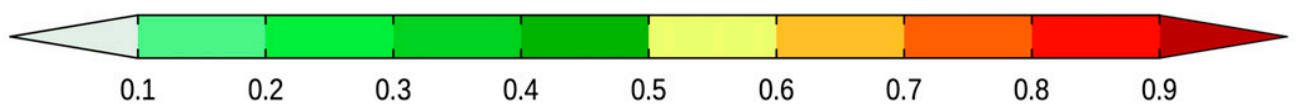

FIG. 11. As in Fig. 9, but for the 850-mb winds from CFSR data regressed on CFSR rainfall indices.

relatively strong agreement (correlation values greater than 0.8 ) between all products. Agreement drops rapidly as one moves eastward across the monsoon region, with correlations generally falling to less than 0.4 in the eastern portion of the domain. This mirrors previous results (Cash et al. 2008b) for a somewhat different suite of data products, indicating that this is a pervasive issue.

These disagreements between the products are of sufficient magnitude to affect conclusions drawn from them for the different regions in quantities such as total mean rainfall, rainfall variability, the association between rainfall in the different regions, the association between regional rainfall and circulation, and the association with SST anomalies. This sensitivity to the choice of product remains true even if comparison is limited to GPCP and CMAP, a somewhat surprising situation given the high degree of overlap between the data sources used in the two products. Our analysis should serve as a cautionary 
(a) Western Ghats

JJAS CFSR $850 \mathrm{mb}$ Winds regressed against GPCP precip

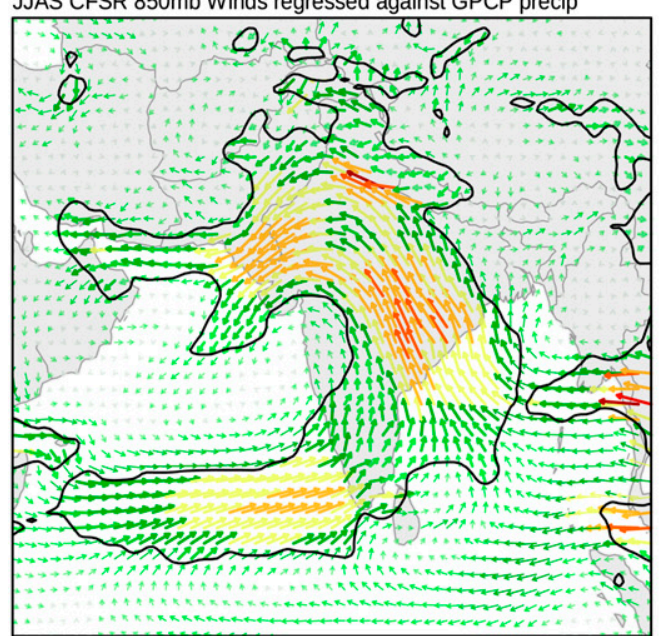

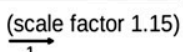

(c) Bay of Bengal

JJAS CFSR $850 \mathrm{mb}$ Winds regressed against GPCP precip

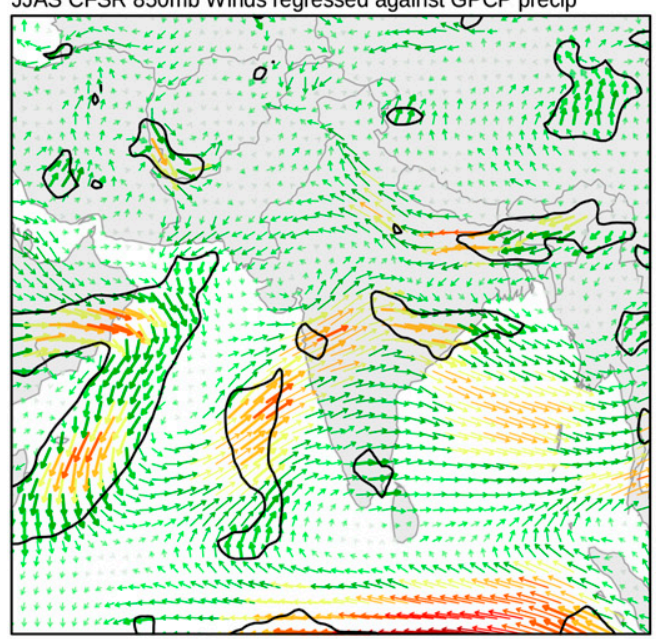

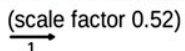

(b) Ganges Basin

JJAS CFSR $850 \mathrm{mb}$ Winds regressed against GPCP precip

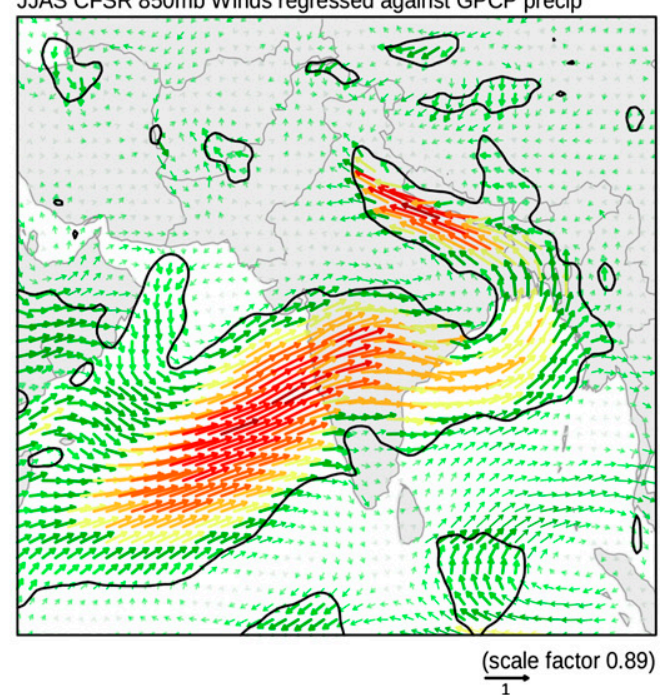

(d) Bangladesh

JJAS CFSR $850 \mathrm{mb}$ Winds regressed against GPCP precip

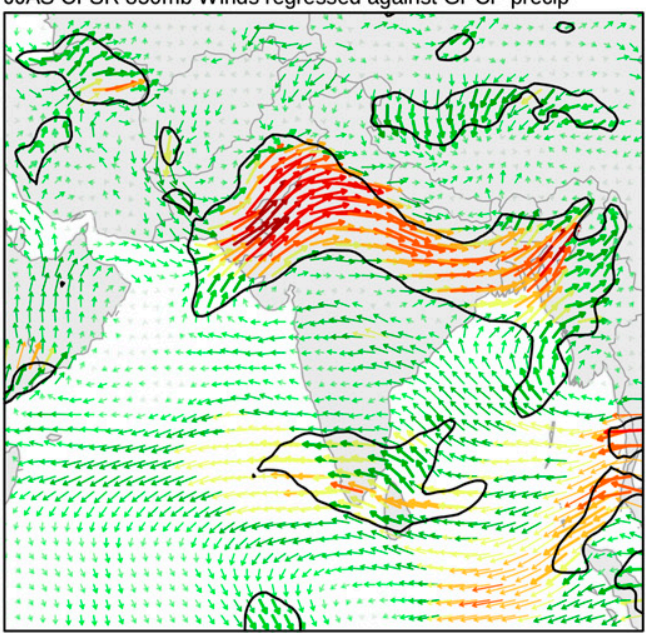

$\stackrel{\text { (scale factor } 0.59)}{\longrightarrow}$

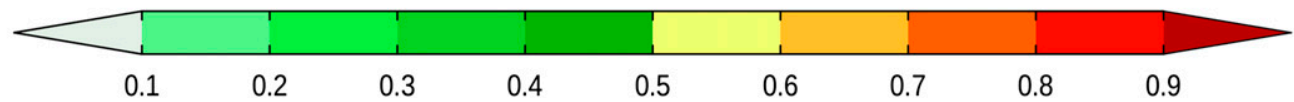

FIG. 12. As in Fig. 11, but regressed on GPCP

note that more than one precipitation product should be consulted for studies in this region to ensure the robustness of the conclusions.

Although the observed rainfall products are inconsistent in representing seasonal mean rainfall anomalies for a given region, CMAP, GPCP, Chen, MERRA, and IFS generally agree that the regions are only weakly or negatively correlated. The precipitation results from the CFSR and ERA-I present a contrasting picture, in which rainfall is strongly correlated across much of the monsoon region. The fact that the MERRA product does not show this broad correlation between regions, a correlation that is not supported by our analysis nor that of previous studies, indicates that this not simply an inherent problem with reanalyzed precipitation and is in fact specific to CFSR and ERA-I (of the reanalyses considered here).

We find that the partitioning of rainfall between the four regions, which we might expect to be dominated by local processes, can be described as due to large-scale 

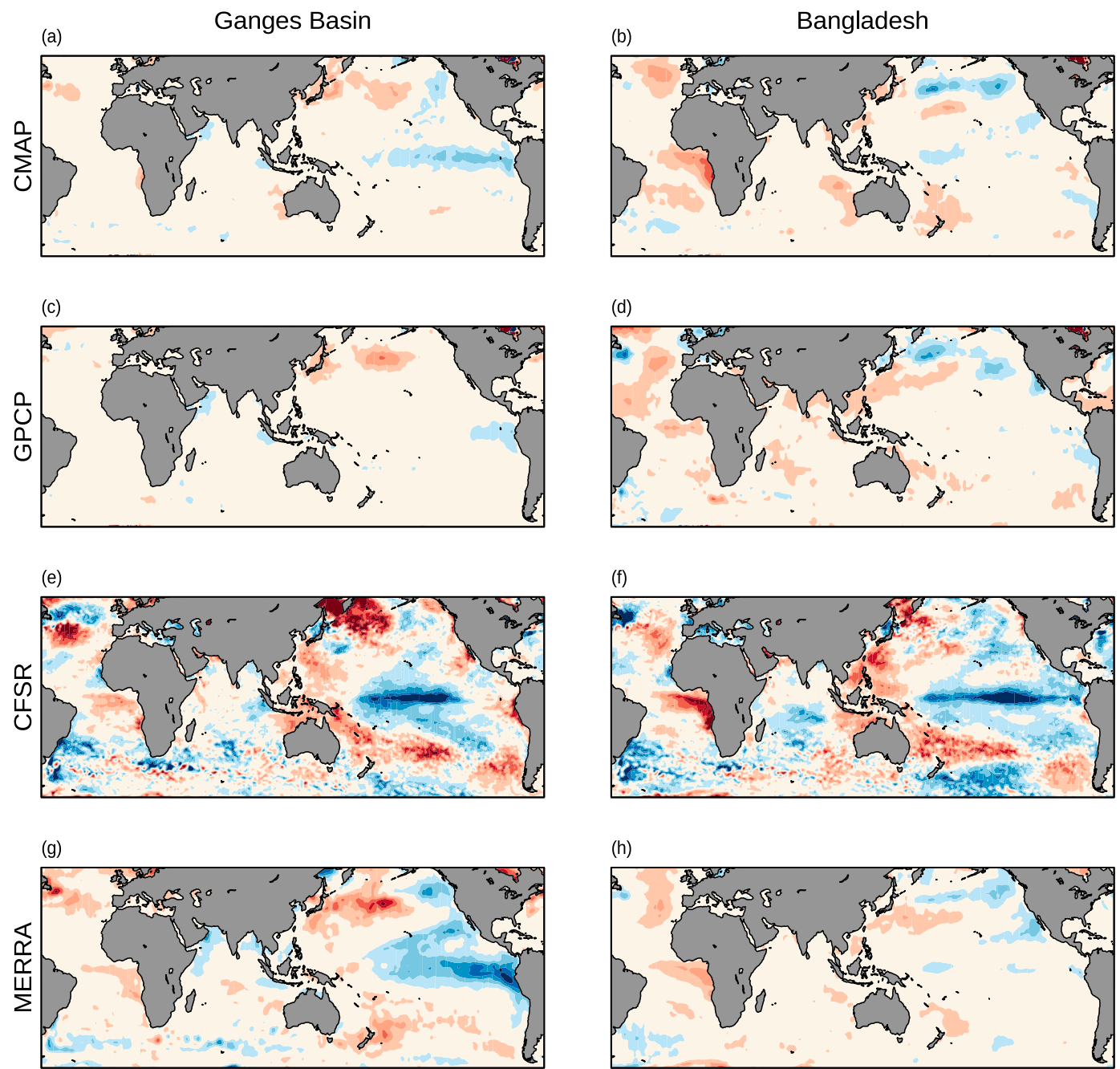

(h)
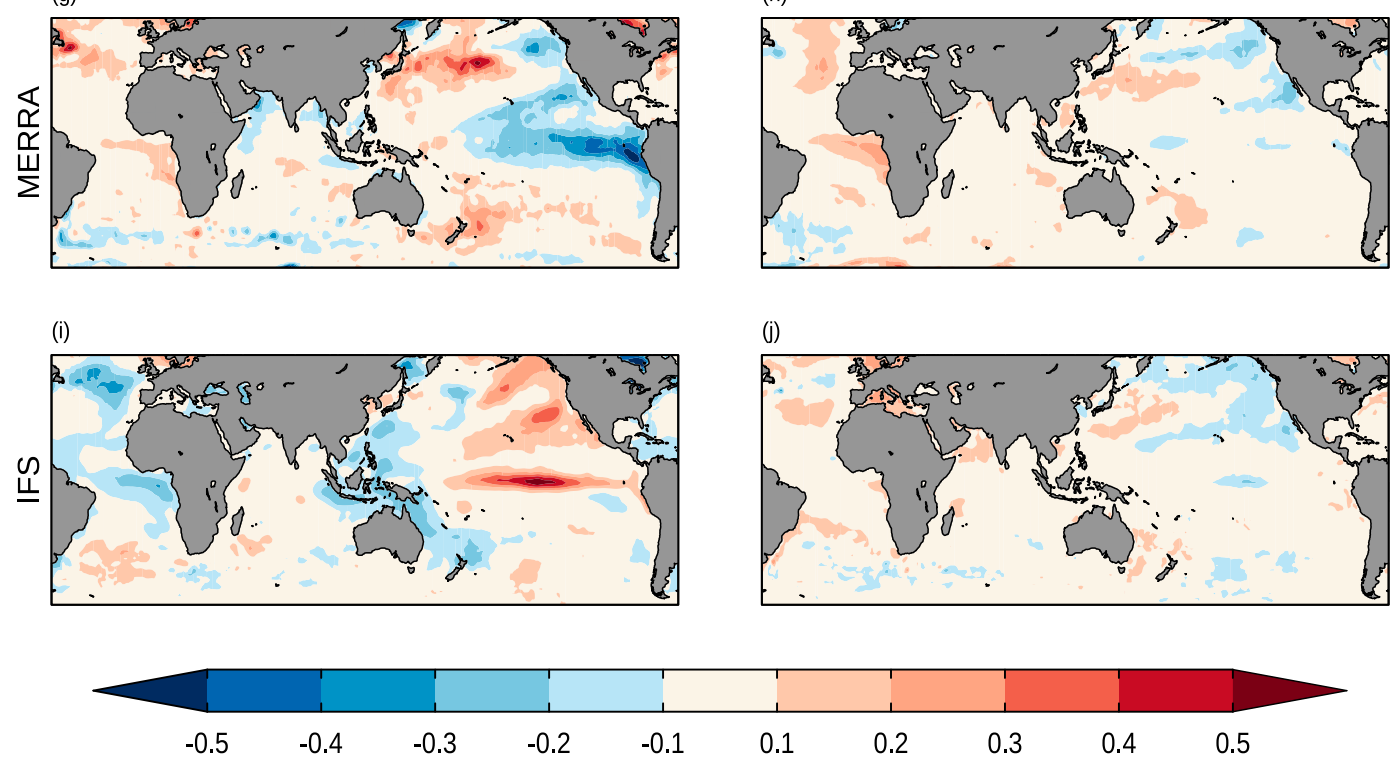

FIG. 13. Regression between JJAS rainfall and SST (K) for (left) GB and (right) BD and (a),(b) CMAP, (c),(d) GPCP, (e),(f) CFSR, (g),(h) MERRA, and (i),(j) IFS. SST data for GPCP and CMAP are from HadISST1.1; SSTs for other panels are from the respective products.

shifts in the center and intensity of the seasonal mean monsoon circulation. A weakening in the strength of the climatological monsoon circulation leads to anomalous westerlies along the southern edge of the Tibetan Plateau, and these anomalies are strongly associated with enhanced moisture convergence and hence rainfall over Bangladesh (see also Cash et al. 2008a). Rainfall in the other three regions considered is associated with easterlies in this same region and an overall strengthening of the monsoon circulation, with small shifts in the center 
of the anomalous cyclonic circulation determining the location of the rainfall maximum.

The association between rainfall and circulation described above is only reproduced when the rainfall and circulation data are taken from MERRA, or if the rainfall is taken from CMAP-GPCP and the circulation from MERRA-CFSR-ERA-I. It cannot be reproduced using the CFSR-ERA-I precipitation, again indicating an issue with those products. The fact that the association can be recovered by substituting CMAP-GPCP precipitation for CFSR-ERA-I precipitation suggests that the winds in the different reanalysis products are more tightly constrained by the observations than the precipitation fields, and that there is an inconsistency between the CFSR-ERA-I precipitation and circulation that is not present in MERRA.

One of the more surprising results to emerge from this analysis is that the rainfall patterns and circulation patterns produced by the IFS integrations are essentially indistinguishable from those of CMAP, GPCP, and MERRA. This is despite the fact that not only are the seasonal rainfall anomalies for the individual regions uncorrelated with the observations, but also the association between rainfall and SST anomalies is significantly different from any of the observed products. This strongly suggests that the remote forcing acts to alter the likelihood of occurrence of a given rainfallcirculation pattern, rather than altering the existing patterns. Accurate representation of the interannual behavior of rainfall thus appears to be independent of an accurate representation of the rainfall structure. In this instance at least an atmospheric model forced with observed SST, but without assimilating any atmospheric data, is capable of outperforming multiple state-of-the-art reanalysis products.

Acknowledgments. The IFS results described herein were obtained in the 2009-2010 Athena Project, a computationally intensive project that was carried out using the Athena supercomputer at the University of Tennessee's National Institute for Computational Sciences (NICS), under the auspices of the National Science Foundation (NSF). Support provided by the NICS, the NSF (Grants 0830068 and 0957884), NOAA (Grant NA09OAR4310058), and NASA (Grant NNX09AN50G) is gratefully acknowledged. We also acknowledge the support of the European Centre for Medium-Range Weather Forecasts (ECMWF), which provided the IFS code, boundary and initial conditions datasets, and run scripts. We are thankful to Dr. Phil Arkin and Dr. V. Krishnamurthy for their comments on an earlier draft of the manuscript. The following individuals contributed to the project: D. Achuthavarier (GSFC);
P. Dirmeyer, B. Doty, C. Stan, and T. Wakefield (COLA); P. Bechtold, M. Fuentes, M. Hamrud, M. Miller, P. Towers, and N. Wedi (ECMWF); T. Palmer (University of Oxford); M. Satoh (University of Tokyo); H. Tomita (RIKEN Advanced Institute for Computational Sciences, AICS); C. Kodama and Y. Yamada (JAMSTEC); P. Andrews, T. Baer, M. Ezell, C. Halloy, D. John, B. Loftis, and K. Wong (NICS); and P. Johnsen and P. Nyberg (Cray, Inc.).

\section{REFERENCES}

Adler, R. F., and Coauthors, 2003: The version 2 Global Precipitation Climatology Project (GPCP) monthly precipitation analysis (1979-present). J. Hydrometeor., 4, 1147-1167, doi:10.1175/1525-7541(2003)004<1147:TVGPCP>2.0.CO;2.

Cash, B. A., X. Rodó, and J. L. Kinter III, 2008a: Links between tropical Pacific SST and cholera incidence in Bangladesh: Role of the eastern and central tropical Pacific. J. Climate, 21, 46474663, doi:10.1175/2007JCLI2001.1.

,,--- M. J. Fennessy, and B. Doty, 2008b: Differing estimates of observed Bangladesh summer rainfall. J. Hydrometeor., 9, 1106-1114, doi:10.1175/2008JHM928.1.

,-- , and -2009 : Links between tropical Pacific SST and the regional climate of Bangladesh: Role of the western tropical and central extratropical Pacific. J. Climate, 22, 16411660, doi:10.1175/2008JCLI2177.1.

,,-- J. L. Kinter, and I. I. I. Md. Yunus, 2010: Disentangling the impact of ENSO and Indian Ocean variability on the regional climate of Bangladesh: Implications for cholera risk. J. Climate, 23, 2817-2831, doi:10.1175/2009JCLI2512.1.

— - - J. Ballester, M. Bouma, R. Dhiman, and M. Pascual, 2013: Malaria epidemics highlight influence of the Tropical South Atlantic on the Indian monsoons. Nat. Climate Change, 3, 502-507, doi:10.1038/nclimate1834.

Chen, M., P. Xie, J. Janowiak, and P. Arkin, 2002: Global land precipitation: A 50-yr monthly analysis based on gauge observations. J. Hydrometeor., 3, 249-266, doi:10.1175/ 1525-7541(2002)003<0249:GLPAYM>2.0.CO;2.

Dee, D. P., and Coauthors, 2011: The ERA-Interim reanalysis: Configuration and performance of the data assimilation system. Quart. J. Roy. Meteor. Soc., 137, 553-597, doi:10.1002/qj.828.

Kinter, J. L., III, and Coauthors, 2013: Revolutionizing climate modeling with Project Athena: A multi-institutional, international collaboration. Bull. Amer. Meteor. Soc., 94, 231245, doi:10.1175/BAMS-D-11-00043.1.

Krishnamurthy, V., and J. L. Kinter III, 2003: The Indian monsoon and its relationship to global climate variability. Global Climate: Current Research and Uncertainties in the Climate System, X. Rodó and F. Comín, Eds., Springer-Verlag, 186236.

Kummerow, C., W. Barnes, T. Kozu, J. Shiue, and J. Simpson, 1998: The Tropical Rainfall Measuring Mission (TRMM) sensor package. J. Atmos. Oceanic Technol., 15, 809-817, doi:10.1175/ 1520-0426(1998)015<0809:TTRMMT>2.0.CO;2.

Parthasarathy, B., K. R. Kumar, and A. A. Munot, 1996: Homogeneous regional summer monsoon rainfall over India: Interannual variability and teleconnections. Research Rep. RR-70, Indian Institute of Tropical Meteorology, Pune, India, $26 \mathrm{pp}$. 
Pascual, M., X. Rodó, S. P. Ellner, R. Colwell, and M. J. Bouma, 2000: Cholera dynamics and the El Niño-Southern Oscillation. Science, 289, 1766-1769, doi:10.1126/science.289.5485.1766.

— , L. F. Chaves, B. A. Cash, and X. Rodó, 2008: Predicting endemic cholera: The role of climate variability and disease dynamics. Climate Res., 36, 131-140, doi:10.3354/cr00730.

Rayner, N. A., D. E. Parker, E. B. Horton, C. K. Folland, L. V. Alexander, D. P. Rowell, E. C. Kent, and A. Kaplan, 2003 Global analyses of sea surface temperature, sea ice, and night marine air temperature since the late nineteenth century. J. Geophys. Res., 108, 4407, doi:10.1029/2002JD002670.

Rienecker, M. M., and Coauthors, 2011: MERRA: NASA's ModernEra Retrospective Analysis for Research and Applications. J. Climate, 24, 3624-3648, doi:10.1175/JCLI-D-11-00015.1.

Rodó, X., M. Pascual, G. Fuchs, and A. S. G. Faruque, 2002: ENSO and cholera: A nonstationary link related to climate change. Proc. Natl. Acad. Sci. USA, 99, 12901-12 906, doi:10.1073/ pnas.182203999.

Saha S., and Coauthors, 2010: The NCEP Climate Forecast System Reanalysis. Bull. Amer. Meteor. Soc., 91, 1015-1057, doi:10.1175/2010BAMS3001.1.
Turner, A. G., and H. Annamalai, 2012: Climate change and the South Asian summer monsoon. Nat. Climate Change, 2, 587595, doi:10.1038/nclimate1495.

Vecchi, G. A., and D. E. Harrison, 2004: Interannual Indian rainfall variability and Indian Ocean sea surface temperature anomalies. Earth Climate: The Ocean-Atmosphere Interaction, Geophys. Monogr., Vol. 147, Amer. Geophys. Union, 247-260.

Walker, G. T., and E. W. Bliss, 1932: World weather V. Mem. Roy. Meteor. Soc, 4, 53-84.

Xie, P., and P. A. Arkin, 1996: Analyses of global monthly precipitation using gauge observations, satellite estimates, and numerical model predictions. J. Climate, 9, 840-858, doi:10.1175/1520-0442(1996)009<0840:AOGMPU>2.0.CO;2. _, and _ 1997: Global precipitation: A 17-year monthly analysis based on gauge observations, satellite estimates, and numerical model outputs. Bull. Amer. Meteor. Soc., 78, 2539-2558, doi:10.1175/1520-0477(1997)078<2539:GPAYMA $>2.0 . C O ; 2$.

Yin, X., A. Gruber, P. Arkin, 2004: Comparison of the GPCP and CMAP merged gauge-satellite monthly precipitation products for the period 1979-2001. J. Hydrometeor., 5, 1207-1222, doi:10.1175/JHM-392.1. 